\title{
Learning under Fear of Floating
}

\author{
Saki Bigio* \\ * Department of Economics \\ New York University
}

\author{
DT. $N^{\circ} 2009-004$ \\ Serie de Documentos de Trabajo \\ Working Paper series \\ Abril 2009
}

Los puntos de vista expresados en este documento de trabajo corresponden a los del autor y no reflejan necesariamente la posición del Banco Central de Reserva del Perú.

The views expressed in this paper are those of the author and do not reflect necessarily the position of the Central Reserve Bank of Peru. 


\title{
Learning under Fear of Floating
}

\author{
Saki Bigio \\ Department of Economics \\ New York University*
}

March 31, 2009

\begin{abstract}
Cross-country evidence suggests that during recent years a large fraction of developing countries seem to began to overcome fear of floating, i.e., a lower relative volatility of exchange rates to monetary policy instruments. To explain this trend, we build a model that describes the behavior of Central Banks in developing countries under uncertainty and fear of misspecification about the effects of exchange rate depreciations. The Central Bank is uncertain about two sub-models which differ in that exchange rate depreciations can cause output either to expand (textbook effect) or contract (balance sheet effect). Optimal policy within the second sub-model is consistent with fear of floating. A feature of fear of floating is that, by preventing sizeable exchange rate swings, Central Banks could loose valuable information useful to distinguish among models.

We describe how the Central Bank's the evolution of the prior depends on the optimal policy and viceversa. We conclude that the trend towards less fear of floating may not be explained by Bayesian or robust policies because it would have been too quick to explain the data. However, if there was a parameter change affecting many countries during the early 2000's, the model generates the observed pattern.
\end{abstract}

Keywords: Balance Sheet Effect, Fear of Floating, Model Uncertainty, Learning, Monetary Policy, Policy Experimentation, Robustness,

JEL Classification: C11,E44,E58,F31,F33

*Saki Bigio: sbigio@nyu.edu. We wish to thank Dave Backus, Francisco Barillas, Ryan Booth, Timothy Cogley, Jonathan Eaton, Boyan Jovanovic, Virgiliu Midrigan, Taisuke Nakata, Kris Nimark, Vicente Tuesta, Marco Vega, Vivian Yue and Eduardo Zilberman for insightful comments. The usual disclaimer applies. 


\section{Introduction}

Cross-country evidence suggests that in recent years, a large number of developing countries seem to moved towards more flexible exchange rates. Central Bankers in these economies often think of exchange rates ${ }^{1}$ as having two potential effects that work on opposite directions. On the one hand, high unexpected depreciations might be beneficial to agents that generate some fraction of their income in foreign currency, (e.g., the exporting sector or agents holding dollar-denominated assets.). Under nominal rigidities, a sudden shift in the value of the nominal exchange rate translates to a sudden shift in the real exchange rate and therefore produces beneficial wealth and competitiveness effects. This is a standard economics textbook effect ${ }^{2}$.

On the other hand, the balance sheet effect is a harmful after-effect that might result from high unexpected exchange rate depreciations if it induces imbalances in the asset-liability positions of economic agents. In underdeveloped financial markets, it is likely that firms have low coverage and the balance sheet effect may have an aggregate effect. This may occur when a large fraction of agents hold assets denominated in domestic currency while holding liabilities denominated in US Dollars. Without insurance to cover them from these losses, exposed firms might face a credit crunch that leads to an aggregate downturn. Theoretical and empirical work to date has formalized this ideas and has documented evidence on the balance sheet effect ${ }^{3}$.

In this paper, we ask if learning about either effect could explain the trend towards more flexible exchange rates. We abstract from the main mechanisms driving either model. We characterize the problem of a Central Bank that has uncertainty over a single parameter that encompasses both effects. Both sub-models are used to guide policy but each of them delivers opposite effects from unexpected exchange rate movements. In this environment, policy makers fear missing the true model because outcomes in terms of the data generating process might render high losses compared.

We first study a Bayesian Central Bank in which acts in the spirit of Brainard (1967). Policy makers react according prior beliefs about either model and update them through Bayes rule. We then explain how this policy and its learning properties are altered when the Central Bank behaves according to a policy consistent with fear of misspecification. That is, we analyze the behavior of a Central Bank that behaves optimally according to multiplier

\footnotetext{
${ }^{1}$ We define the exchange rate as the domestic currency price of the US Dollar.

${ }^{2}$ See for example Clarida et al. (2001) and Gali and Monacelli (2005) for versions of open economy models with nominal rigidities in which the textbook effect is present.

${ }^{3}$ See Aghion et al. (2000), Aghion et al. (2001), Caballero and Krishnamurthy (2001), Krugman (1999), Céspedes et.al (2002), Chang and Velasco (2004), Schneider and Tornell (2004) and Frankel (2005) for theoretical work. See Hausmann et al. (2001) and Calvo and Reinhart (2002) for empirical evidence.
} 
preferences as described in Hansen and Sargent (2006) and Hansen and Sargent (2007b).

The tested hypothesis of this paper is that Central Banks around the world put a strong prior during the early nineties and that it took them more than a decade to learn that they where wrong. In the context of the model, slow learning could have been caused by a fear of floating policy: do to initial uncertainty, no important exchange rates swings are allowed while this swings enable a quick detection of the true structure. Hence, fear of floating policies may have induced slow model learning which further sustained the fear of floating policy. In this context, these economies would have moved towards more flexible exchange rates slowly.

In spite of being a reasonable explanation, this potential trap is inconsistent with the model. When we calibrate the model to reasonable parameters we found that learning is expected to occur in about five years for both Bayesian and robust policies. This is a faster pace than what we found in cross-country data. On the other hand, the pattern could be explained if there was a parameter change from the balance-sheet model to the textbook model common to many developing during the early 2000's. This reconciliation suggests that perhaps, there was an international trend towards less exchange rate exposure of these economies following the financial crisis of the 1990's.

The nature of the problem we present here is closely related to other recent works that studies the behavior of Central Banks under model uncertainty. This paper follows the work by Wieland (2000a), Wieland (2000b), Ellison (2006), Cogley et al. (2007), Ellison, Sarno and Vilmunen (2007) and Cogley et al. (2008). Most of these papers focused on uncertainty about the sacrifice ratio implied by the Phillips curve and the benefits of policy experimentation in closed economies. Among these papers, Ellison, Sarno and Vilmunen (2007) is the closest to ours. That paper studies uncertainty about the exchange rate in a two-country setup in which devaluations have effects through the relative price of imports to exports. Our paper differs from theirs not only by the nature of uncertainty but also because we pay special attention to the pace at which the Central Bank under Bayesian and robust policies learn under a model close to the ones used by Central Banks.

The title is suggestive: this paper tries to explain learning under fear of floating and fear of misspecification. For these purpose, we proceed as follows: In the following section we describe how the symptoms of systematic fear of floating across countries have been weaker during the last 4 years. In section 2 we introduce a benchmark small open economy model and in section 3 we present an analytical solution to the optimal Bayesian Central Bank policy under passive learning. In section 4 we explain how multiplier preferences alter this policy and how Robust policies are equivalent to Bayesian policy with a distorted prior. In section 5 we discuss the learning properties of these Central Bank policies and time varying 
parameters. We conclude in section 6 .

\subsection{Evidence on Learning under Fear}

Hausmann et al. (2001) and Calvo and Reinhart (2002) describe exchange rate interventions in different countries. Their finding suggests that during the nineties decades, many developing countries had lower relative variance of the exchange rate depreciations over the interest rates than developed economies. These studies suggest that countries that shared this feature were countries in which the Central Banks intervened often. The consensus is that developed countries suffered from a fear of floating phenomenon which was rationalized by balance sheet effects.

What if Central Banks where not sure about the presence of the balance sheet effect? Would they be able to learn over time? To answer these questions, we constructed two graphs based the statistic suggested by Hausmann et al. (2001) (hereafter HPS-statistic). Figure 1 compares the relative volatility of exchange rate depreciations and interest rates for 40 countries $^{4}$. The HPS-statistic reflects the degree of intervention in exchange rate markets using nominal interest rates. A low statistic shows high intervention. For a Bayesian Central Bank, relatively low HPS-statistics are consistent with putting a strong prior to the balance sheet model independent of the structure.

The sample of countries is restricted to a sample of economies for which the statistic is at most 6 . There are three panels in the figure. Panel (a) is a cross country scatter plot of the statistic for 2 different periods: the $\mathrm{x}$-axis shows the average statistic the period 19941998 and the y-axis for 1999-2004. The solid line is a 45-degree line. Countries close to the 45-degree line had a stable HPS-statistic over both periods. The closer the points to this line the more stable were the policies. Panel (a) is consistent with Hausmann et al. (2001) and Calvo and Reinhart (2002) in that the ranking of exchange rate interventions remained constant through time: countries like Australia, Canada or Japan still intervene less than Peru, Ukraine or Uruguay.

Panel (b) is the same as Panel (a) for the 1999-2004 sample against the 2005-2008 sample. Panel (c) depicts with arrows the change in each country's position from panel (a) to panel (b). Panel (c) shows an international trend: a movement out of the 45-degree line. Note that the majority of developing countries in the beginning sample are clustered around the 45-degree line in panel (a). This suggests that during the 1990's developing countries

\footnotetext{
${ }^{4}$ The data was obtained from the International Financial Statistics provided by the International Monetary Fund. The panel includes 40 countries. Exchange rates correspond to the money markets. The interest rates are the Central Bank's discount rate when available which are replaced by the inter-bank rate when the figure is not available. The data covers the months between January 1994 and December 2008 as the broadest range. The author provides the data set in his webpage
} 


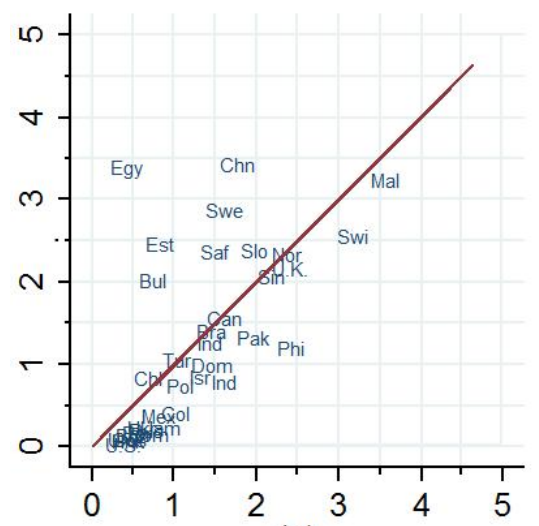

(a)

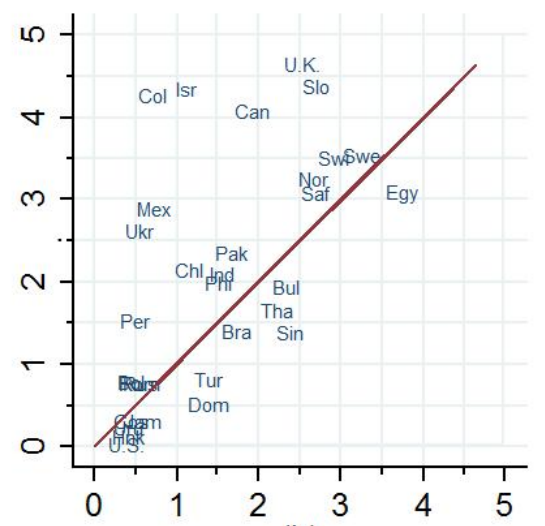

(b)

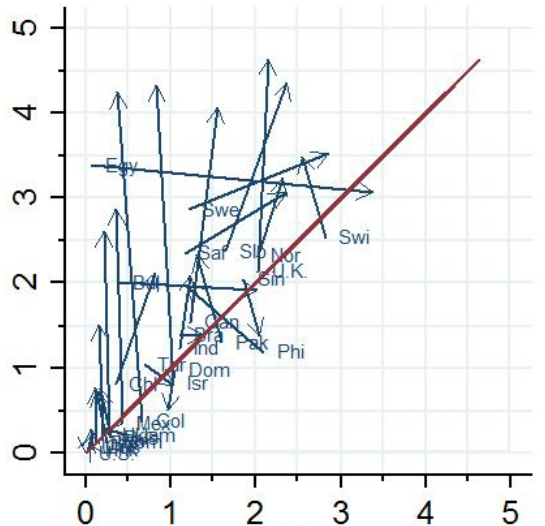

(c)

Figure 1: Cross Country HPS-statistic: The figure plots the HPS-statistic for countries with a low statistic (high intervention) for different sample periods. Panel (a) plots the statistic computed for 1994-1998 (x-axis) against 1999-2003 (y-axis). Panel (b) plots the statistic computed for 1999-2003 (x-axis) against 2004-2008 (y-axis). Panel (c) shows the change from panel (a) to panel (b). The solid line depicts the 45-degree line. Countries close to the line had a stable statistic.

constantly intervened in exchange rate markets although across countries the implied statistic was different. Surprisingly, the pattern is not repeated in the center panel. The bulk of developing countries in the sample jumped to a higher statistic revealing a trend towards more flexible regimes. That is, there is evidence that most of the countries in the sample show a change from a remaining with a low statistic for the first 2 sub-samples and suddenly began to allow more volatility in the exchange rate during the last 4 years.

This shows an international trend towards more flexible exchange rates. It is plausible to think more of a change in policy rather than having the data driven by common shocks since the sample periods are long, of about 50 months on average per period. On the other hand, when the sample is restricted to the group of least intervention, the pattern is lost, suggesting that the pattern is only constant among countries suffering fear of floating at the beggining 5 .

To check if the evidence is robust to a common took trends out of the data. Detrending would reduce any artificial increase in the variance of exchange rates by changes on the mean. Figure 2 mimics Figure 1 for HP-filtered data. The overall picture is that the evidence is

\footnotetext{
${ }^{5}$ In fact, the 1990's were a period in which exchange rate interventions by Central Banks were constantly discussed by policy makers and researchers. See for example: Chang and Velasco (2000), Ize and Levy-Yeyati (2003), Levy-Yeyati and Sturzenegger (2003), Levy-Yeyati and Sturzenegger (2003), Chang and Velasco (2004) or Goodhart (2005).
} 


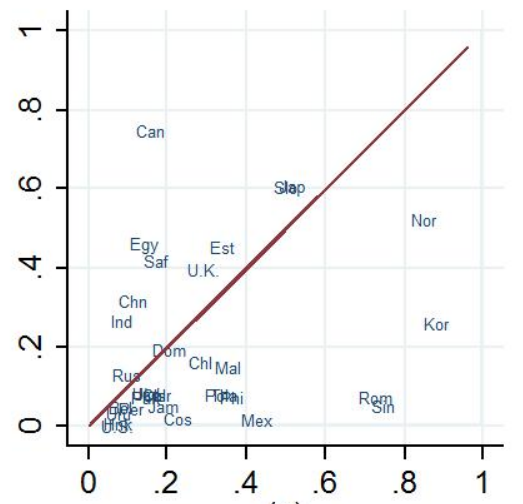

(a)

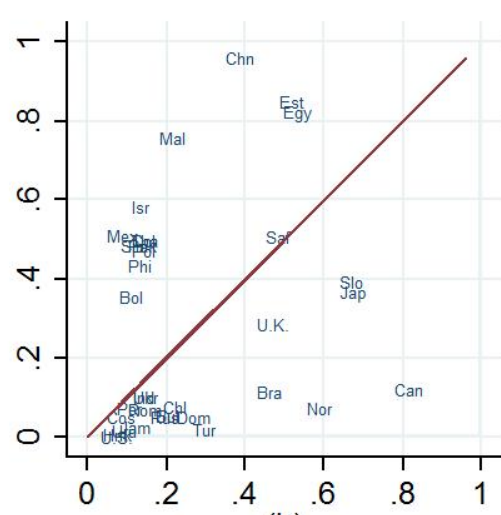

(b)

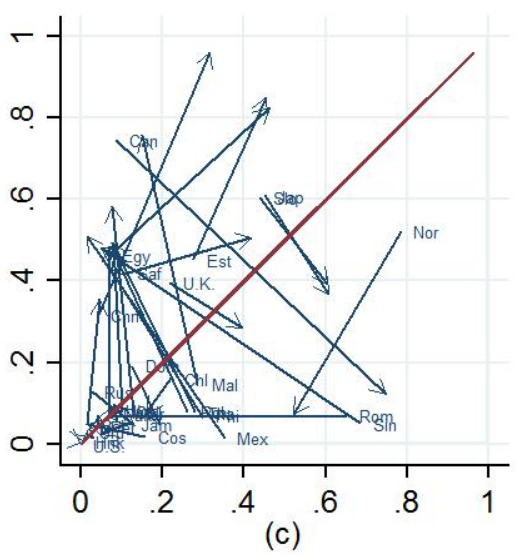

(c)

Figure 2: Cross Country HPS-statistic for HP-filtered data. The figure plots the HPSstatistic for countries with a low statistic (high intervention) for different sample periods. The data was filtered using the Hodrick-Prescott filter with parameter 40000. Panel (a) plots the statistic computed for 1994-1998 (x-axis) against 1999-2003 (y-axis). Panel (b) plots the statistic computed for 1999-2003 (x-axis) against 2004-2008 (y-axis). Panel (c) shows the change from panel (a) to panel (b). The solid line depicts the 45-degree line. Countries close to the line had a stable statistic.

not as strong, but still, one can find a pattern.

We test the hypothesis that many developing countries assigned a strong prior to the balance sheet model at the beginning of the sample and that they learned, towards the 2000's, that their fear was unfounded.

\section{A Standard Small Open Economy Model}

We use a standard new-keynesian small-open economy model as our workhorse since it is a benchmark for Central Banks around the world. The exact structure here is close to Ball (1999) and Gali and Monacelli (2005). The model of Gali and Monacelli (2005) begins from proper micro-foundations that include monopolistic competition and nominal rigidities which is the reason why nominal variables have real effects.

As in all New-Keynesian models, we have a Phillips curve:

$$
\pi_{t}=\beta E_{t}\left[\pi_{t+1}\right]+\gamma y_{t}+\varepsilon_{\pi, t}
$$

where $\pi_{t}$ is the inflation rate, $y_{t}$ is the output gap and $\beta$ is the period discount factor. Inflation also depend depends on the expectation of inflation $E_{t}\left[\pi_{t+1}\right]$ of the following periods 
inflation and the output gap $y_{t}{ }^{6} . \varepsilon_{\pi, t}$. The term $\varepsilon_{\pi, t}$ represents a cost-push shock.

In addition, there is an aggregate demand equation:

$$
y_{t}=E_{t}\left[y_{t+1}\right]-\chi\left(i_{t}-E_{t}\left[\pi_{t+1}\right]-r_{t}^{n}\right)+\theta E_{t}\left[\triangle s_{t+1}\right]+\varepsilon_{y, t}
$$

Equation 2 is the aggregate demand equation that describes how the output gap depends on it's own one period ahead expectation term, the gap between the real interest rate and its natural level $r_{t}^{n}$, the expected nominal depreciation $E_{t}\left[\triangle s_{t+1}\right]$ and a demand shock $\varepsilon_{y, t}$. The textbook model will have $\theta$ to be positive. Therefore, nominal devaluations will expand output. The balance sheet model works the opposite way with $\theta$ being negative. The nominal interest rate $i_{t}$ is controlled by the Central Bank so we will refer to it as its policy instrument.

The expected nominal exchange rate depreciation $E_{t} s_{t+1}-s_{t}$ is obtained via an uncovered interest rate parity equation:

$$
E_{t}\left[\triangle s_{t+1}\right]=i_{t}-i_{t}^{*}-\varepsilon_{e t}
$$

This is a non-arbitrage condition between domestic $i_{t}$ and foreign interest rates $i_{t}^{*}$. We call the shock to this equation a financial shock $\varepsilon_{e, t}$.

The natural interest rate $r_{t}^{n}$ evolves according to the following law of motion:

$$
r_{t}^{n}=\rho_{n} r_{t}^{n}+\varepsilon_{t}^{r}
$$

and $\varepsilon_{t}^{r}$ is a shock to this autoregressive process. The system is characterized by the following set of parameters which are constant over time: $\left[\beta, \gamma, \chi, \theta,\left\{\rho_{s}, \mu_{s}, \sigma_{s}^{2}\right\}_{s=\pi, y, e, i, r}\right]$.

Notice that the model does not include terms of trade as other new-keynesian model do. In fact, Lubik and Schorfheide (2007) have shown that at least for Australia, Canada, New Zealand and the UK, the terms of trade in the model of Gali and Monacelli (2005) are not important for the business cycle. Hence, one can be comfortable that this simplification will not alter the results.

The model is very similar to its closed economy counterpart as suggested by Clarida et al. (2001). Following Clarida et al. (2002), the Central Bank will seek to minimize a standard quadratic loss function ${ }^{7}$ :

\footnotetext{
${ }^{6}$ Notice that the small Open Economy Phillips Curve presented here ignore the Pass-Through mechanism. This mechanism would not add much to a discussion on whether the textbook effect or the balance sheet effect dominates.

${ }^{7}$ This loss function is analogous to the Closed Economy Version of this model. Recent papers have provided microfoundations of a welfare function in the Small Open Economy that differ from this one. Faia and Monacelli (2008) show that home bias in consumption is a sufficient condition for introducing the exchange rate into the objective. De Paoli (2009) also argues that the exchange rates should be included when the economy faces monopolistic competition in domestic and foreign goods.
} 


$$
L_{\tau}=E_{\tau}\left[\sum_{t=\tau}^{\infty} \beta^{t-\tau}\left(\pi_{t}^{2}+w y_{t}^{2}\right)\right]
$$

The minimization is constrained by a set of equations 1, 2, 3 and 4 described above. In the new Keynesian framework, Central Banks are concerned about stabilizing output because it puts pressure on inflation and because deviations from its steady state are inefficient when the market is not competitive and there are nominal frictions.

The timing protocol of the models is as follows: all shock processes $\varepsilon_{s, t}$ for $s=\pi, y, e, i, r$, follow an $A R(1)$ process with corresponding set of parameters $\left\{\rho_{s}, \mu_{s}, \sigma_{s}^{2}\right\}$. We denote the innovations to these processes by $\nu_{s, t}$ correspondingly. We further assume that all the $\varepsilon_{s, t}$ innovations are observed only after one period lag except for the $\varepsilon_{\text {et }}$ risk premium shock that affects the depreciation expectations and the world interest rate shock $\varepsilon_{i, t}$. This assumption is supported by the fact that spot exchange rates are observed as well as nominal domestic and world interest rates are observed immediately.

Under this protocol, optimal policies with certainty will be the limit cases of the Bayesian policies we describe below. We can obtain the optimal policy discretionary policy (without commitment) as a function of parameters and observed shocks. In the rest of the paper, we focus on the optimal discretionary as opposed to commitment policies. Credible policies under commitment for a Central Bank remains an unresolved question in economics. The optimal policy, steady state equilibrium and other properties are described in appendix A.

\section{Optimal Bayesian Policy}

A Bayesian Central Bank that ignores whether data is generated by model A or B, will act in accordance to a model prior probability assigned to each and maximize expected utility. In dynamic setups, the Central Banker may incorporate the fact that his policies will affect his ability to learn. Here, Central Banks are assumed to be myopic, in the sense that they won't take into account the effect that their actions will have on their ability to learn. ${ }^{8}$. Active learning wouldn't affect the results since as we will show, learning would have been too fast even without experimentation.

\footnotetext{
${ }^{8}$ In a related paper, Bigio and Vega (2006), study wether intentional policy experimentation could be beneficial. In their model, the balance sheet effects has a quadratic effect on output. In spite of this nonlinearity, no substantial gains from intentional policy experimentation are found. This is a result in line with the one obtained by Cogley et al. (2007) and Cogley et al. (2008). We keep the focus of the discussion here to passive learning policies. In contrast Wieland (2000a) and Wieland (2000b) shows that intentional policy experimentation is beneficial and may avoid policy traps
} 


\subsection{Knowledge Assumptions}

The only particular feature about knowledge assumption is to assume that $\theta$ has an unknown value to both policy makers and agents within the model. Recall that $\theta$ is the parameter that translates exchange rate depreciations to an effect in the output gap. In addition we adopt the common prior assumption. By doing so, uncertainty becomes common knowledge and does not require solving the problem of 'forecasting the forecast of others' ${ }^{\prime}$. A theorem in Aumann (1979) asserts that under this assumption, posteriors coincide too.

\subsection{The Bayesian Central Bank's Problem}

When Central Bankers are uncertain about which of the two possible is the actual model driving the economy they assign a probability $p_{t}$ to model $\mathrm{A}$ and a probability $\left(1-p_{t}\right)$ to model B. This probability evolves according to the odds ratio, i.e, a combination of model fit and their shocks and an initial prior belief $p_{0}$.

Note that the uncertainty is constrained to only two values of parameters. In fact, we could have chosen to model this source of uncertainty as a density over the values of $\theta$. In fact the optimal policy in the case of 2 parameter values is the same optimal policy for a continuum of parameters if we choose an appropriate prior density (though using Bayes rules as an updating rule could change these relation after one period). The advantage of restricting the parameter space is that each parameter has the interpretation of a different model: the textbook and the balance sheet model. In further sections, this point will be more clear.

By only taking into account this simple version of uncertainty the expected loss function for period $t$ becomes

$$
L\left(p_{\tau}\right)_{\tau}=p_{\tau} L_{\tau \mid A}+\left(1-p_{\tau}\right) L_{\tau \mid B}
$$

Where $L_{\tau \mid A}$ and $L_{\tau \mid B}$ represent the value functions conditional on model A or B being the true models. Note that because in the passive learning environment the priors are fixed, the prior can be taken as a parameter. To avoid notation, model A will refer to the textbook model and model B to the balance sheet model. The loss function 6 is consistent with expected utility theory. The optimal policy will be a function of the prior belief and current available information. The following proposition describes this optimal policy:

Proposition 1 (Optimal Bayesian Policy). The optimal Bayesian monetary policy without

\footnotetext{
${ }^{9}$ Ellison (2006) makes the same assumption for the same reason.
} 
commitment is obtained is given by the following rule:

$$
i_{\tau}^{B A Y}\left(p_{\tau}\right)=\frac{1}{\Psi\left(p_{\tau}\right)}\left[\left(\chi_{\pi}+\frac{\gamma_{y}}{w}\left(\frac{1}{\rho_{\pi}}-1\right)\right) \Lambda \rho_{\pi} \varepsilon_{\pi, \tau-1}+E_{\tau}\left(\mu_{y, \tau} \mid p_{\tau}\right)\right]
$$

where

$$
\Psi\left(p_{\tau}\right)=\chi-\left(p_{t} \theta^{H}+\left(1-p_{t}\right) \theta^{L}\right)
$$

and

$$
\mu_{y, t}=\chi r_{t}^{n}-\theta i_{t}^{*}-\theta \varepsilon_{e t}+\varepsilon_{y, t}
$$

The detail of the solution to the Central Bank's problem is presented in the appendix.

The optimal policy reacts to all of the shocks to the model by weighting there effects into the loss function. The reaction to shocks depends on the sign of $\Psi\left(p_{\tau}\right)$, which in turn, depends on the prior. In fact the sign of the policy reaction may even change depending on the prior (the next section provides detail for a particular calibration). Also note that because the optimal policy depends on expectations of shocks that are not observable, the set of state variables to compute the optimal policy includes all the shocks to the system while including two demand shocks: one for each model. Hence, computing optimal policies requires computing the demand shocks for both models.

The update of model A probability in the Bayesian approach depends on Bayes odd's ratio:

$$
p_{t}=P\left(M^{A} \mid \text { Data }\right)=\frac{P\left(\text { Data } \mid M^{A}\right) P\left(M^{A}\right)}{P\left(\text { Data } \mid M^{B}\right) P\left(M^{B}\right)+P\left(\text { Data } \mid M^{A}\right) P\left(M^{A}\right)}
$$

The intuition behind this ratio is that the probability that the policy maker will assign to a given model for being true will depend on a weighted average (with weights given by the previous periods model probabilities) of the likelihood of the data at period $t$ conditional to each model and the data. In section 5 we describe how the priors converge to the true model, i.e., the how Central Banks learn.

By holding priors fixed we can understand some things about the learning dynamics of this policy. We can observe that the smaller the variance of expected devaluation, $E_{t}\left[\triangle s_{t+1}\right]$, the smaller will be the difference between the implied residuals of equation 2 according to Models A and B. Thus the likelihood ratio will be close so the prior will evolve slower. When the balance sheet effect is severe, the variance of expected devaluation will be smaller when the prior $p_{t}$ is closer to 0 because the balance sheet model will suggest stronger stabilization of the financial shock. This is feature is consistent for the fear of floating economies Calvo and Reinhart (2002).

No matter what the prior is, it can be shown that under this policy, $P_{t}$ converges almost 
surely to the true model. Kasa (1999) provides a formal treatment on conditions for these result. Intuitively, the fact that agent's will always learn the true model in this context occurs because fixed exchange rates are never optimal in this setup. Because this is the case, on average the true model will yield a lower error term in the aggregate demand equation, making it's likelihood function higher. This property comes from the fact that uncertainty is described over a single parameter. In general, with uncertainty over more parameters, this assertion is not necessarily true. Therefore, the focus of our description is on the speed of learning rather than conditions that ensure learning at all. The next section describes benchmark calibration of the model and its main features.

\subsection{Calibration and Dynamics}

Our calibration is designed so that the textbook model and the balance sheet model indicate the policy maker react to financial shocks in opposite directions. This property stressed by the earlier studies on the balance sheet model, Aghion et al. (2000). The Bayesian optimal policy is a convex combination of both policies. We illustrate the model's dynamics implies by different priors. In particular, we want to stress how asymmetric are responses according to the prior because this will have important consequences on learning. In this exercise we fix prior the prior in order to have a clear idea on what is the expected behavior of Central Banks after a shock to the uncovered interest rate parity (or exchange rate shock) ${ }^{10}$.

We calibrate the model according to the following approach: we take the parameters in equations 2, 1 and 3 according to the estimation done by Lubik and Schorfheide (2007) for the Canadian economy. The parameters that determine the structure of the shock are chosen to mimic the Bank of Canada's Quarterly Projection Model described in Murchison and Rennison (2006). We chose Canada as our benchmark small open economy for model A because it represents a small open economy that has developed financially in such a way that the balance sheet is not present. On the other hand, the HPS-statistic for Canada was not as high as Australia or New Zealand, but the close enough to countries that seam to suffer from fear of floating at the beginning of the sample but not at the end. We calibrated $\theta_{A}$ and the variance of the process to match the HPS-statistic of Canada, and the volatility of devaluations and interest rates. To parameterize model B, we chose $\theta_{A}$ to match the HPSstatistic of Peru, an example of a fear of floating economy ${ }^{11}$. The summary is presented in table 1:

\footnotetext{
${ }^{10}$ Other Impulses responses are available in the authors webpage. We left the interpretation for the reader. All the impulse responses are centralized in codes available in the author's webpage.

${ }^{11}$ Our model is a simplification of any of the models describe. We interpreted variables and tried to replicate the model's impulse responses as close as possible.
} 


\begin{tabular}{|lll|}
\hline Parameter & Value & Notes \\
\hline Reduced form parameters & & \\
\hline$\beta$ & 0.99 & Specifying a quarterly model with 4 per cent steady-state real interest rate \\
$\gamma$ & 0.86 & Following Lubik and Schorfheide $(2007)$ \\
$\chi$ & 0.37 & Following Lubik and Schorfheide $(2007)$ \\
$w$ & 0.5 & Putting $2 / 3$ of wheight on inflation and $1 / 3$ on output \\
\hline Shock process parameters & & \\
\hline$\rho_{\pi}$ & 0.7 & Guided by Bank of Canada's Quarterly Projection Model ${ }^{12}$ Price Mark-Up Shock \\
$\rho_{y}$ & 0.2 & Guided by Bank of Canada's Quarterly Projection Model Demand Shock \\
$\rho_{r}$ & 0.3 & Following Lubik and Schorfheide (2007) estimate of terms of trade estimate \\
$\rho_{i}$ & 0.8 & Consistent with Libor data \\
$\rho_{e}$ & 0.35 & Guided by Bank of Canada's Quarterly Projection Model Risk Premium (Exchange Rate) Shock \\
$\sigma_{\pi}$ & 0.15 & Guided by Bank of Canada's Quarterly Projection Model Price Mark-Up Shock \\
$\sigma_{y}$ & 0.18 & To match volatility of interst rates and devaluations in Canda \\
$\sigma_{r}$ & 0.5 & Following Lubik and Schorfheide (2007) estimate of terms of trade estimate \\
$\sigma_{i}$ & 0.25 & Consistent with Libor data \\
$\sigma_{e}$ & 0.08 & To match volatility of interst rates and devaluations in Canda \\
\hline Model A and B & & \\
\hline$\theta_{A}$ & 0.1 & To match Canada's HPS-statistic \\
$\theta_{B}$ & -0.6 & To match Peru's HPS-statistic \\
\hline
\end{tabular}

Under this parameterizations we can have a good idea of the exchange rate policy behind the optimal policy by observing the impulse responses functions shown in figures 3 and 4 . The impulse we analyze is a negative financial shock (exchange rate shock). A negative shock of this type will put pressure towards appreciation. The plots show a continuum of impulse responses for each prior. The darkest lines indicate the behavior when the Central Bank was closer to certainty, that is, when the prior was either close to 1 or close to 0 . As the lines get lighter, this means that the prior was of more uncertainty about either model.

Arrows in the figure point out the outcome under the optimal policy for each model (a prior of 1 or 0 ). One can see in both figures that if the Policy Maker knows the true model he is able to stabilize both output and inflation perfectly. Under model A the optimal policy makes the Central Bank reduce interest rates. It does so because interest rates will have two effects that offset each other exactly stabilizing the output gap. On the one hand, a reduction in the interest rates provokes a further appreciation according to the uncovered parity (equation 3). Because under model A, the aggregate demand (equation 2) reacts negatively to the appreciation but positively to the reduction in interest rates, the policy is designed in such a way that both effects exactly offset each other.

Under model B, the effects appreciations work the opposite way. Appreciations cause output to expand, but the belief that output will contract prescribes to lower rates. This pushes the depreciation even further on and deviations are even stronger.

Under certainty, there is no tension between stabilizing output and inflation because the model lacks a pass-through rate. A 0 pass-through rate is unlikely in an open economy but for many countries pass-through rates are usually not high ${ }^{13}$. Our assumption implies

\footnotetext{
${ }^{13}$ Lubik and Schorfheide (2007) shows that it is low for industrialized economies. Monacelli (2005) studies
} 
that the costs of nominal devaluations are due to model uncertainty rather than a sacrifice ratio trade-off caused by pass-through. This will matter when we calculate Robust policies because distorted probabilities will only respond to uncertainty and will not try be respond to this trade-off.

When the Central Banks assigns a positive prior to both models, the policies are the same during the first period after the shock is realized. In subsequent periods, the policies are different because the Central Bank will belief that there was a demand shock for the false model. Because it assigns a non-zero prior to that model, and the shock has serial correlation, in subsequent periods, the policy is reacting partially to an expected shock in aggregated demand too. The wrong model is predicting subsequent demand shocks.

The cost of missing the true model manifests itself through in through deviations from the steady state inflation and output (upper right and lower left panel). Under model A, the textbook model, a Central Bank assigning a low prior will increase interest rats inducing a fall on output and a deflation. Fear of a floating induces the wrong policy prescription.

When the true model is model $\mathrm{B}$, the balance sheet model, and the prior assigned to this model is low, the Central Banks acts by reducing rates, thus causing an output expansion and an undesired inflation.

One additional feature of missing the correct prior is that interest rates show an acceleration effect: the peak increase (decrease) in rates is not immediately after the shock occur. Rather, when beliefs are far from truth, after the shock is realized, the Central Bank puts a high prior on the event that the economy was also hit by a demand shock. The Central Bank estimates shock according to the wrong model and finds it was positive when in fact it did not exist. Because shocks have memory, in subsequent periods it reacts to the exchange rate shock and a demand shock that never happened. This phenomenon translates into the hump-shape of impulse responses when the prior is wrong. In the lines of Chari et.al (2002), this property of the model adds additional persistence of real exchange rates through monetary policy reactions.

Because losses are weighted differently depending on the model, we observe that the Bayesian policy is asymmetric. For a prior of 0.5 , the reaction after the shock is closer to the reaction under the balance sheet model because outcomes are much worse under this model. This condition will have effects over Robust policies.

The differences of the optimal policy under each model will affect the HPS-statistic. Figure 5 shows the expected statistic for different priors for both models. The when a high prior is assigned to the balance sheet model, the figure shows that the statistic is much smaller. This image is consistent with the fear of floating literature. The figure also shows optimal policies in low pass-through environments. 

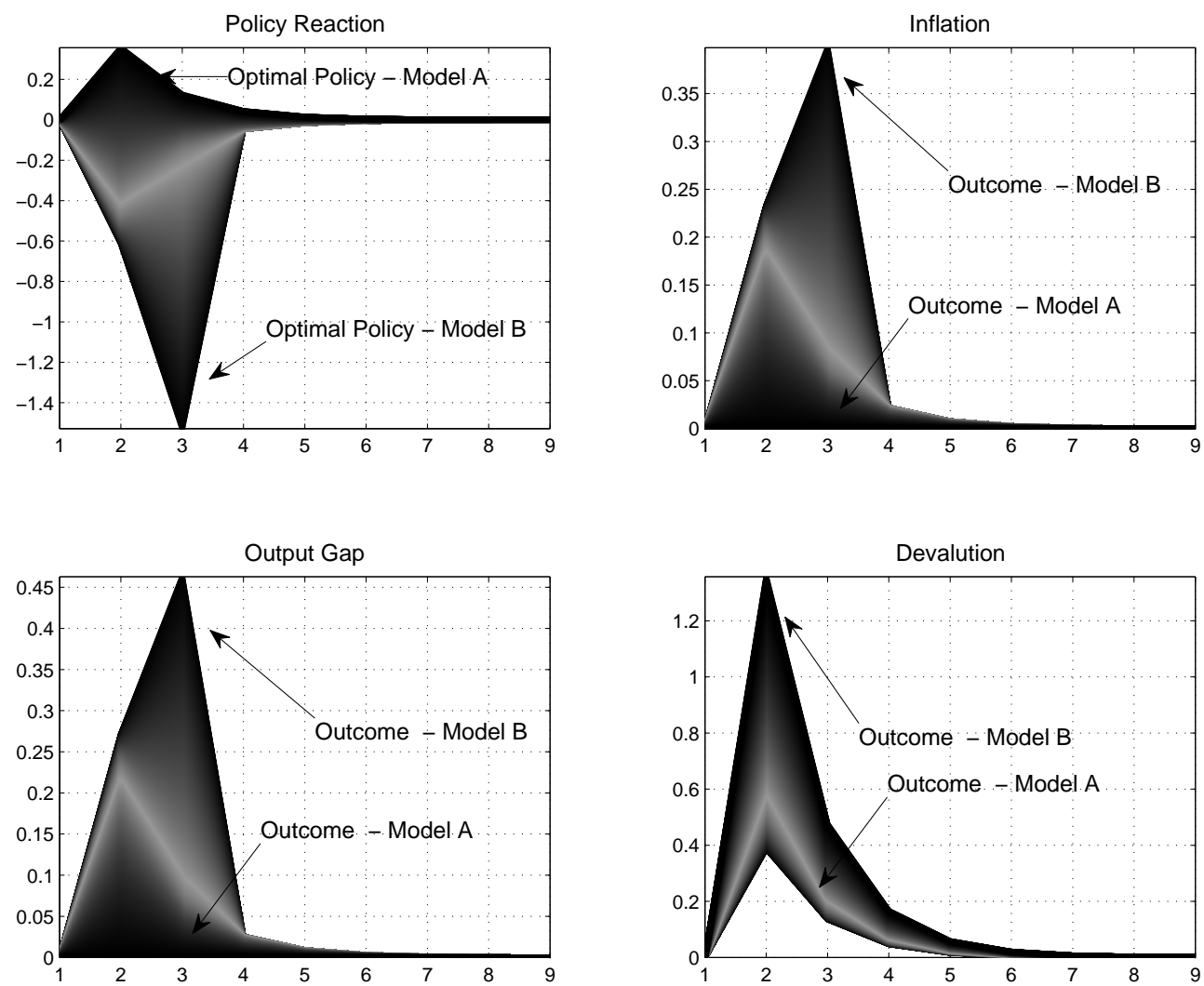

Figure 3: Bayesian Impulse Response - True Model A: The figure shows the reaction of al the endogenous variables after a positive Financial Shock. This shocks puts pressure towards devaluation. Darker colors reflect priors closer to certainty. The lighter color is put on the prior with 0.5 probability. 

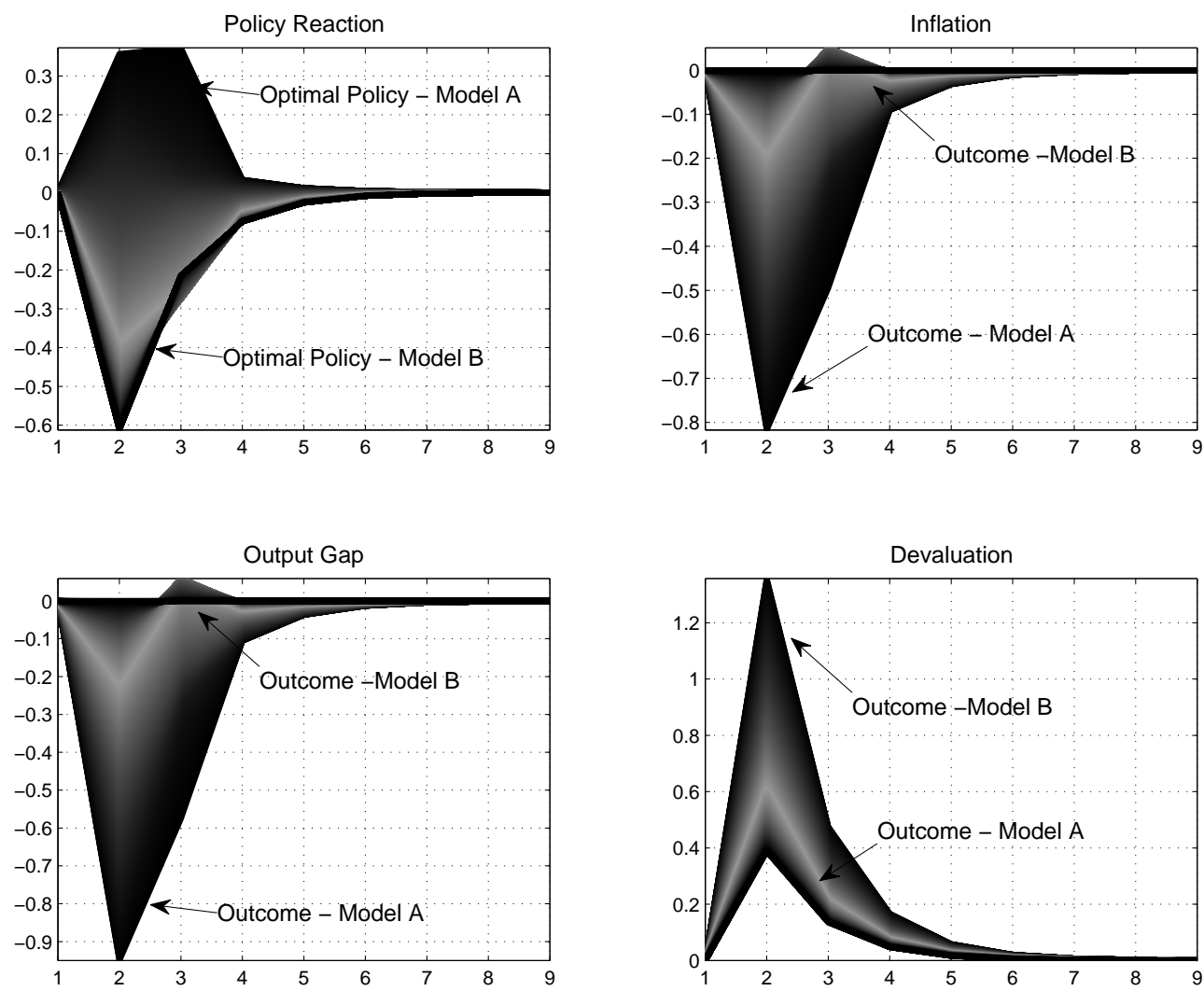

Figure 4: Bayesian Impulse Response - True Model B: The figure shows the reaction of al the endogenous variables after a positive Financial Shock. This shocks puts pressure towards devaluation. Darker colors reflect priors closer to certainty. The lighter color is put on the prior with 0.5 probability. 


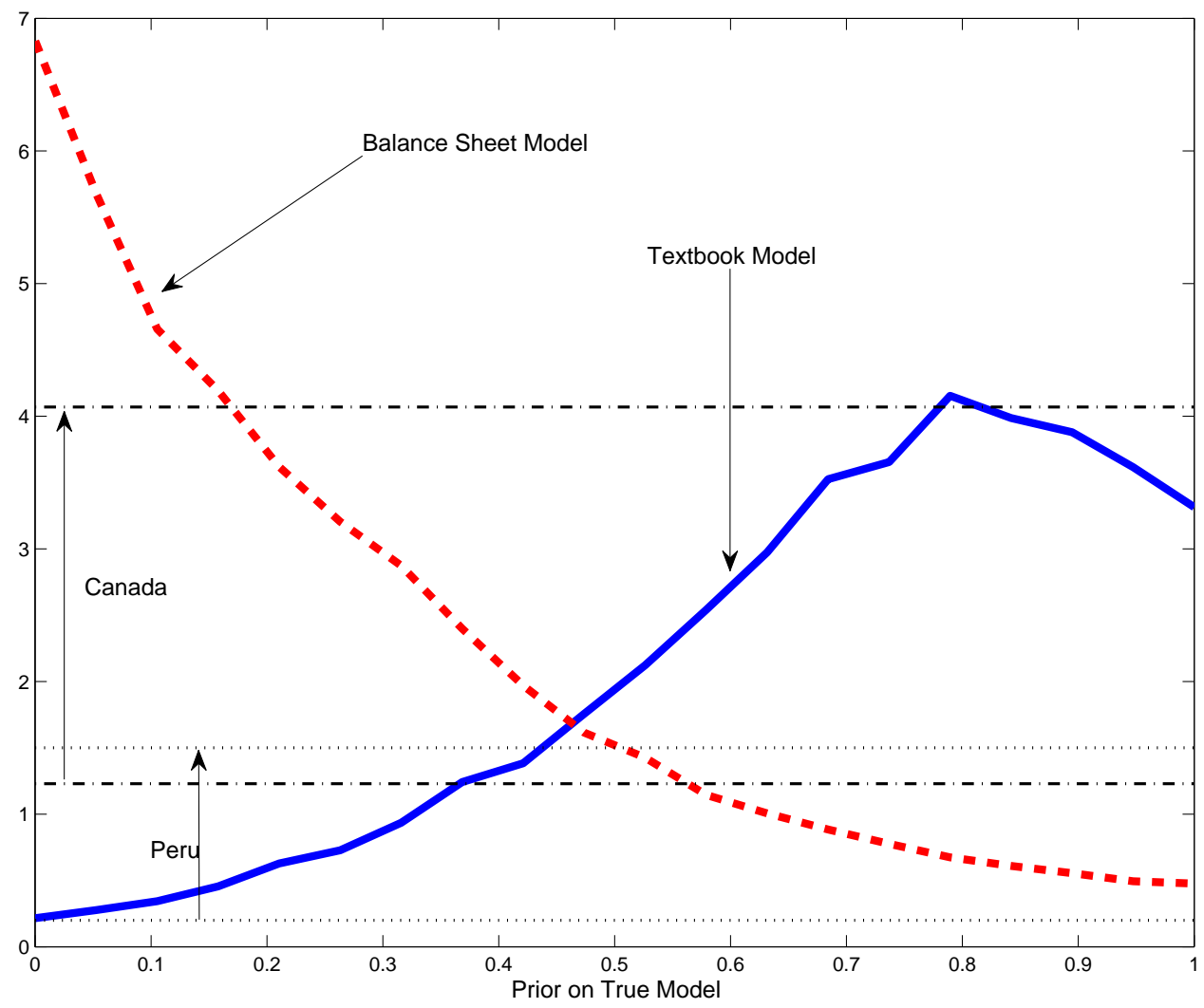

Figure 5: HPS-statistic implied by model

an additional perverse consequence of the balance sheet model. Volatility is extremely high when the balance sheet effect is disregarded. When we solve for Robust policies, this feature will have important effects on how the Central Bank will distort his priors. The figures also include the statistic for Canada and Peru. The arrows show the direction of the increase of the statistic from the first sub-sample to the last sub-sample. Though the statistic is itself a random variable, the figure is consistent with the argument that an increase in the statistic would show signs of learning about model A. Peru could have faced more shocks in the last sample, but a potential alternative story is that it has slowly started to discover that the textbook model applies to its economy. 


\section{Robust Policy}

In section 3 we described how learning about the effects of exchange rate depreciations may occur in less decade when the Central Bank is Bayesian under our calibration. In this section, we assume that the Central Bank has a fear of misspecification of his prior probabilities and hence, optimizes not in accordance to multiplier preferences instead of expected utility theory. Hansen and Sargent (2006) and Hansen and Sargent (2007b) provide substantial support to use these preferences as a modeling device that summarizes fear of misspecification. The idea here is that Central Banks can fear that their updating rules are misspecified. They does not fully trust Bayes rule. There are two reasons that may suggest that Central Bankers in countries that face a potential balance sheet effect may be particularly concerned about misspecification. The first reason is that in spite of observing aggregate data, central bankers constantly may receive information from the private sector. Microeconomic evidence on the balance position of firms with foreign lenders and the banking system may be inconsistent with aggregate effects but the Central Bank does not know how to incorporate this evidence. On the other hand, interest groups may have incentives to complain about strong exchange rate movements. Finally, perceived financial fragility from balance sheet's solely, may neglect the fact that firms can renegotiate their loans to imply the same real burden as before. In fact, firms may be covered against unforseen exchange rate movements in several ways that include forward-back operations. Coverage mechanisms may be hard to observe by central banks.

The second reason is purely statistical: Bayes rule requires additional knowledge. It requires Central Banks to put a priori knowledge on the distribution of economic shocks. Even if shocks are believed to be Gaussian, central bankers are required to know the true variance in advance.

By using Robust policies, the Central Bank will use Bayes rule as a pivotal mechanism to asses risks, but will minimize loss for a set of priors close to the one computed by the data and Bayes rule. Hansen and Sargent's framework deals with two sources of misspecification ${ }^{14}$.

Robust preferences are characterized by a single parameter, $\Theta^{15}$. The higher this parameter is, the more will the central Bank trust it's prior. The robust policy maker solves the following problem:

\footnotetext{
${ }^{14}$ For example, in Cogley et al. (2008) two operators are defined to deal with both forms of fear of misspecification. In this paper, we concentrate only on the later of this. The following problem is close to what they define as their $\mathbf{T}^{2}$-operator only case.

${ }^{15}$ To avoid confusion, this parameters is $\theta$ in Hansen and Sargent's notation. Here $\theta$ refers to the exchange rate parameter in the aggregate demand equation.
} 


$$
L\left(p_{\tau}\right)_{\tau}=\min _{\left\{\bar{p}_{\tau}\right\}} \max _{\left\{i_{t}\right\}}\left\{\bar{p}_{\tau}\left[-L_{\bar{p}_{\tau} \mid, A}+\Theta \log \left(\frac{\bar{p}_{\tau}}{p_{\tau}}\right)\right]+\left(1-\bar{p}_{\tau}\right)\left[-L_{\bar{p}_{\tau} \mid B}+\Theta \log \left(\frac{1-\bar{p}_{\tau}}{1-p_{\tau}}\right)\right]\right\}
$$

Here $p_{\tau}$ is the same prior probability as in the problem defined in section 3 . The Central Banker acts as if there exists a malevolent agent that attempts to distort the prior probabilities assigned to each of the models. This artificial agent is not entirely free to choose any value, but is constrained by a multiplier, $\Theta$ in this case, that summarizes the Central Banker's fear of missespecification. Without this restriction, the artificial evil agent would choose the balance sheet model always for the reasons discussed in the previous section. Hence, higher values of $\Theta$ allows the evil agent lower distortions to the prior, $\Theta=$ inf allows no distortions at all. A Central Bank with strong concerns about Robustness will set $\Theta$ very low, and the evil agent will distort probabilities accordingly.

The game represented by 9 is played simultaneously. The minimizing agent will therefore take a sequences $\left\{i_{t}\right\}$ of policy decisions as given and minimize the Welfare function. The first order and sufficient condition for the artificial minimizing agent is:

$$
\left[-L_{\bar{p}_{\tau} \mid, A}+\Theta \log \left(\frac{\bar{p}_{\tau}}{p_{\tau}}\right)\right]-\left[-L_{\bar{p}_{\tau} \mid B}+\Theta \log \left(\frac{1-\bar{p}_{\tau}}{1-p_{\tau}}\right)\right]+\Theta=0
$$

so regrouping and clearing out this equation yields:

$$
\left(\frac{\bar{p}_{\tau}}{1-\bar{p}_{\tau}}\right)=\left(\frac{p_{\tau}}{1-p_{\tau}}\right) \exp \left[\frac{L_{\bar{p}_{\tau} \mid, A}-L_{\bar{p}_{\tau} \mid B}}{\Theta}\right]
$$

This equality says that if the loss originated from model $\mathrm{A}$ is bigger than the loss caused by model $\mathrm{B}$, the Central Banker will act according to $\bar{p}_{\tau}>p_{\tau}$. Note that for at least some value of the preference parameter, there is well defined mapping from $p_{\tau}$ to $\bar{p}_{\tau}$. Once we obtain $\bar{p}_{\tau}$ the problem for the Robust Central Bank is the same as in section 4. This condition is also used in Cogley et al. $(2008)^{16}$. The main distinction here is that the Phillips curve and output gap equations depend on the agent's expectations. Dealing with Robust in contexts in which there agent beliefs affect the law of motion of variables has not yet been dealt in the in the literature. In the next subsections I describe an assumption that simplifies this complication and allows to compute the value function for each model for a given prior.

\footnotetext{
${ }^{16}$ In particular in these preferences are consistent with ?? setting $\theta_{1}=\infty$ and $\theta_{2}=\Theta$.
} 


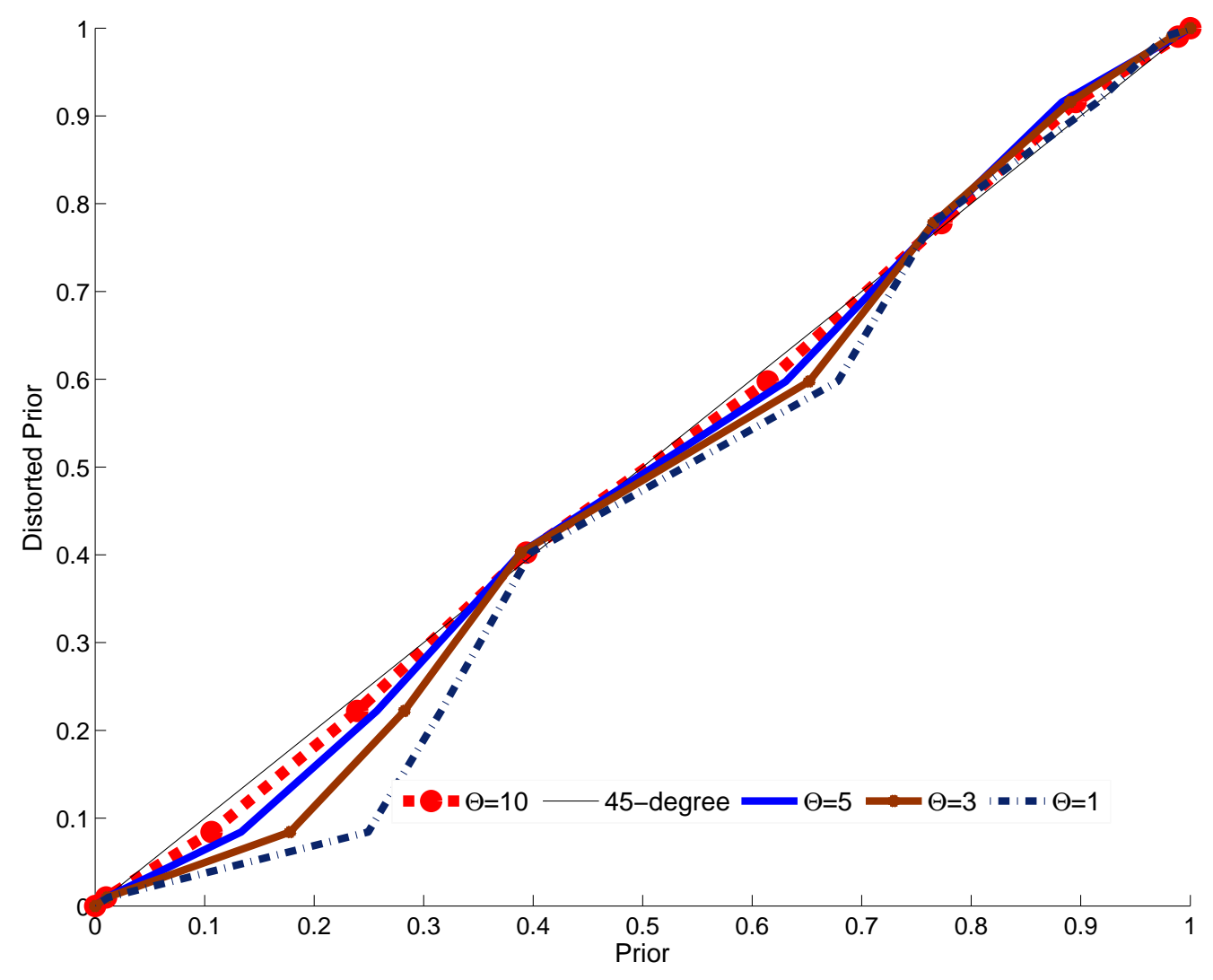

Figure 6: Distorted Prior from Robust Policy and Bayesian Prior. After a devaluation shock of 1 standard deviation.

\subsection{Knowledge Assumptions and Optimal Policy}

We maintain the assumptions of proposed in section 3. In addition we assume that expectations of agents in equations 2 - 3 are constructed in such a way that they are based upon the same prior model belief that assigns the same distorted probability $\bar{p}_{\tau}$ to the Central Bank does. This assumption indirectly suggests that when agents derive there optimal pricing strategies that give rise to the Phillips curve, they do so in such a way that the distorted probabilities are identical to the Central Bank. 


\subsection{Distorted Probabilities and Policies}

Robust policies will depend on a distorted probability calculated from 10 . Once this probabilities are computed ${ }^{17}$ the optimal robust policy replaces the prior in 23 for the distorted prior. The state space has multiple dimensions. Therefore, in this section we describe the distortions of probabilities for a given financial shock as an example. Nevertheless, it is clear that other realizations of shocks will generate different distortions.

The value functions conditional on the true model depend on the current shock realization. Because for some priors, distinct realizations of shocks may induce a worse outcome from one model or the other, it will be the case that Robust policies may tilt the prior towards one model and tilt it towards another model for a different realization. Figure 6 plots, on the vertical axis plots the distortion over the prior over model $\mathrm{A}$ for each value of the prior over model A in the horizontal axis. The shock is 1 standard deviation devaluation of the exchange rate. All alternative shocks are set to 0 in this exercise to stress the effects on the exchange rate. Each curve around the 45-degree lines show distortions under different values of $\Theta$.

The figure shows that when model A is the true model, upon a devaluation, the Robust central banker will react as if its Bayesian prior were closer to model B. This implies an interest policy that reacts with more strength to exchange rate devaluations. From the analysis carried out in the previous sections we could interpret the points in which the distorted probabilities tilt the prior towards model B, as points in which learning will occur at a slower pace. Nevertheless, Robustness will work in the opposite direction for a shock of the opposite sign. Thus, it is clear that the effect of fear of misspecification will affect learning depending on the nature of the shock and its sign. The effect of Robust policies will be described in the following section when we present some simulations based on Bayesian and Robust policies.

The reason for this ambiguity is hinted by Hansen, Sargent and Tallarini (1999) and Adam (2004). In the latter paper, it is shown that for concerns about the nature of the shocks affecting the economy, for well defined robust preferences, there is equivalent Bayesian problem. In our framework, the nature of Robustness differs. It only operates over the prior and not over the perceived law of motion for the shocks. Nevertheless, the distorted prior, by shifting the weight from one model to the other seems operate in an analogous way to a change in the distribution of the shocks. The difference thus, between robustness concerns over the priors are a more restrictive concern than over the shocks nature. For the set of models they analyze These authors find that the optimal robust policy will have an equivalent

\footnotetext{
${ }^{17}$ See Appendix $\mathrm{C}$ for the numerical algorithm.
} 
optimal Bayesian problem if the risk aversion parameter is perturbed. Because our model has the property that the model that yields a worst outcomes depends on the shock, this seems to suggest that robustness will not tilt the prior consistently towards one model or the other. This then suggests that learning under robust policies should not be dramatically different from the Bayesian counterpart. We explore this in the next section.

\section{$5 \quad$ Model Dynamics and Learning}

\subsection{Learning Under Bayesian Policies}

For the calibration described in table 1. Figure 7 explains the speed of convergence of the prior probability departing from initial values for the prior and the model. Solid lines report the expected ${ }^{18}$ path for priors depending on the correct model: model A (solid) and model $\mathrm{B}$ (dashed). The horizontal axis of the graph we have the time elapsed where the scale is quarters. The vertical axis measures the value of the prior so that the curves represent the mean of the prior model evolution.

When the true model is $\mathrm{A}$, we find that beginning from a prior of 10 per cent the expected waited time for converging to a prior probability of 90 per cent is slightly above 5 years, roughly, the time interval of each of our cross-country sub-samples. The learning process is very similar independently of the model. The dashed and solid lines are very close to each other.

The conclusion from this graphs is that following a strictly optimal Bayesian policy, the Central Bank needs about from 4 to 5 years to detect the true model when the economy is initiated with a the wrong prior. In spite of being a long time, this 4 to 5 years seems faster than what we observe in the data. If the textbook effect had been the true structure of the economy, we would have expected to see the systematic increase in volatility at the panel (a) of figure 1 not in panel (b). In the next section we ask if concerns for model misspecification can explain the pattern.

\subsection{Learning Under Robust Policies}

Figure 8 describes the speed of convergence to the true model by replicating 7 when Robust policies are implemented. The figures are based on a value of $\Theta=2^{19}$ We could have chosen a tighter parameter but results did not change much for small perturbations. Moreover

\footnotetext{
${ }^{18}$ Expectations approximated by 20000 replications. The simulations are initiated with a shock to the exchange rate and the other shocks set to 0 .

${ }^{19}($
} 


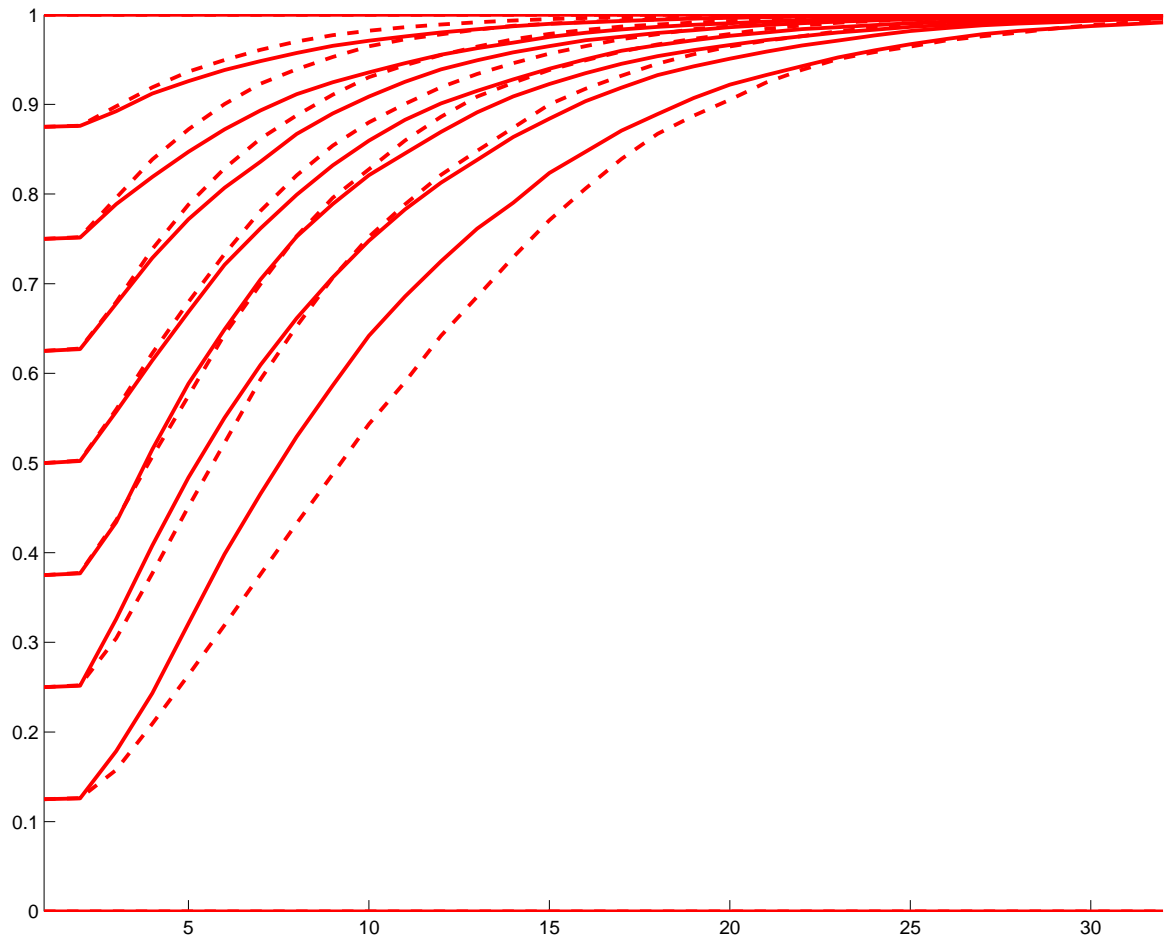

Figure 7: Prior Evolution for Bayesian Policy: Solid lines show the evolution of priors towards Model A when Model A is the true model. Dashed lines show the evolution of priors towards Model B when Model B is the true model. Simulations are carried out considering Bayesian policies based on updated priors. 


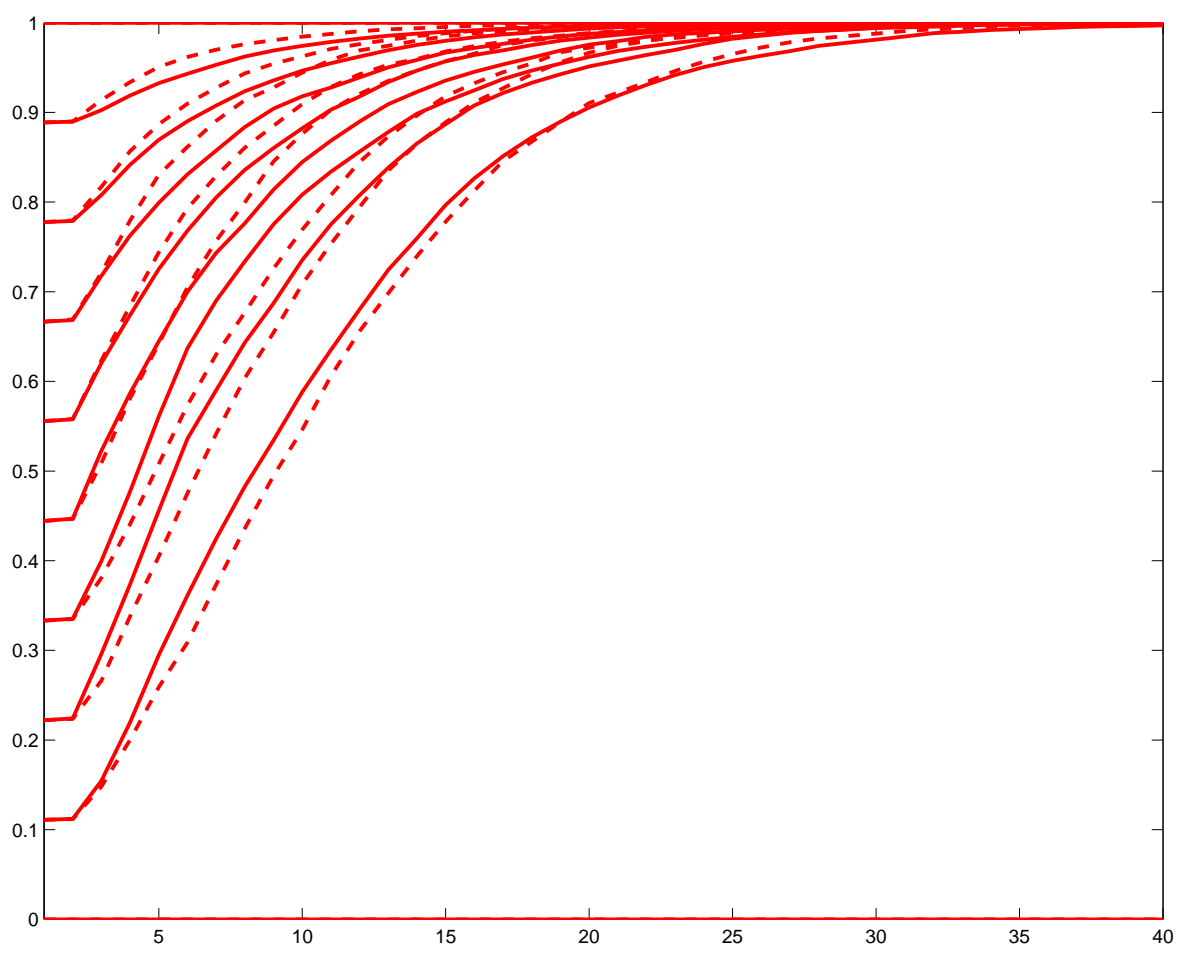

Figure 8: Prior Evolution for Robust Policy: Solid lines show the evolution of priors towards Model A when Model A is the true model. Dashed lines show the evolution of priors towards Model B when Model B is the true model. Simulations are carried out considering Robust policies based on updated priors.

concerns for Robustness cannot be taken much further. The problem becomes ill-posed for values of $\Theta=0.8$ ). The main conclusion that we obtain from the graph is that learning is not modified substantially as expected. That is, the result is consistent with the conjecture that this is due to the fact that Robustness works as a change in risk aversion. If this is the case, because outcomes are worst in one model depending on the realization of shocks, robustness wouldn't tilt the prior systematically towards either model modifying the propensity to learn. A detail inspection though, suggests that learning seems to occur faster, under Robust policies. 


\subsection{Learning with Time Varying Parameters and Cross Country Correlations}

The previous sections show that neither Bayesian optimal or robust policies could account for a learning pattern slow enough to explain international towards more flexible exchange rates. In this section we test an alternative. Here we assume that $\theta$ evolves according to a 2-state Markov process. In particular, we calibrate the model such that $\operatorname{Pr}\left\{\theta_{t+1}=\theta_{A} \mid \theta_{t}=\theta_{A}\right\}=0.99$ and $\operatorname{Pr}\left\{\theta_{t+1}=\theta_{B} \mid \theta_{t}=\theta_{B}\right\}=0.99$, so that the process is highly autocorrelated. This information is common knowledge and the priors are updated accordingly to this process. The Markovian structure followed by this process is aimed to capture the fact that international events, could the structure to switch from one to the other. We have in mind episodes in which after financial crises, international financial institutions begin to ask borrowers in developing countries to purchase costly insurance mechanisms against exchange rate movements, thus preventing the balance sheet to dominate. The reverse could happen once when the position of international financial markets strengthens, and developing country lenders are no longer asked to hedge.

With this intuition in mind, Figure 9 shows the expected behavior of the prior when it is started at 0.1 , and the Markov process for $\theta$ is such that $\theta=\theta_{B}$ for 30 periods and it rapidly switches to $\theta=\theta_{A}$. When this is the case, the model can indeed account for the rapid change towards more flexible exchange rates (the prior moves quickly towards the textbook model). This figure shows that if for many countries, there was a structural change during some point in the early 2000's, the model could easily account for the movement away from fear of floating.

Figure 10 shows a replica of Panel C in 2. A replica of 41 simulated countries for the same sample size experiencing a parameter change from the balance sheet model to the textbook model at the middle of the sample. The figure shows again the pattern away from the 45-degree line. This shows that the trend towards more flexible exchange rates observed in the data, could be explained by the model if there was a parameter change during the early 2000's.

It remains unclear what type of structural change could affect developing countries altogether. It is likely though, that the period after the currency crises induced market regulations on capital markets such that it forced parties to hedge against risks. On the other

hand, privately, agents participating on these markets may have adopted financial contracts that preventing either party from suffering losses due to currency mismatches. This section suggests that there could be an explanation of this sort behind a trend towards more flexible exchange rates. 


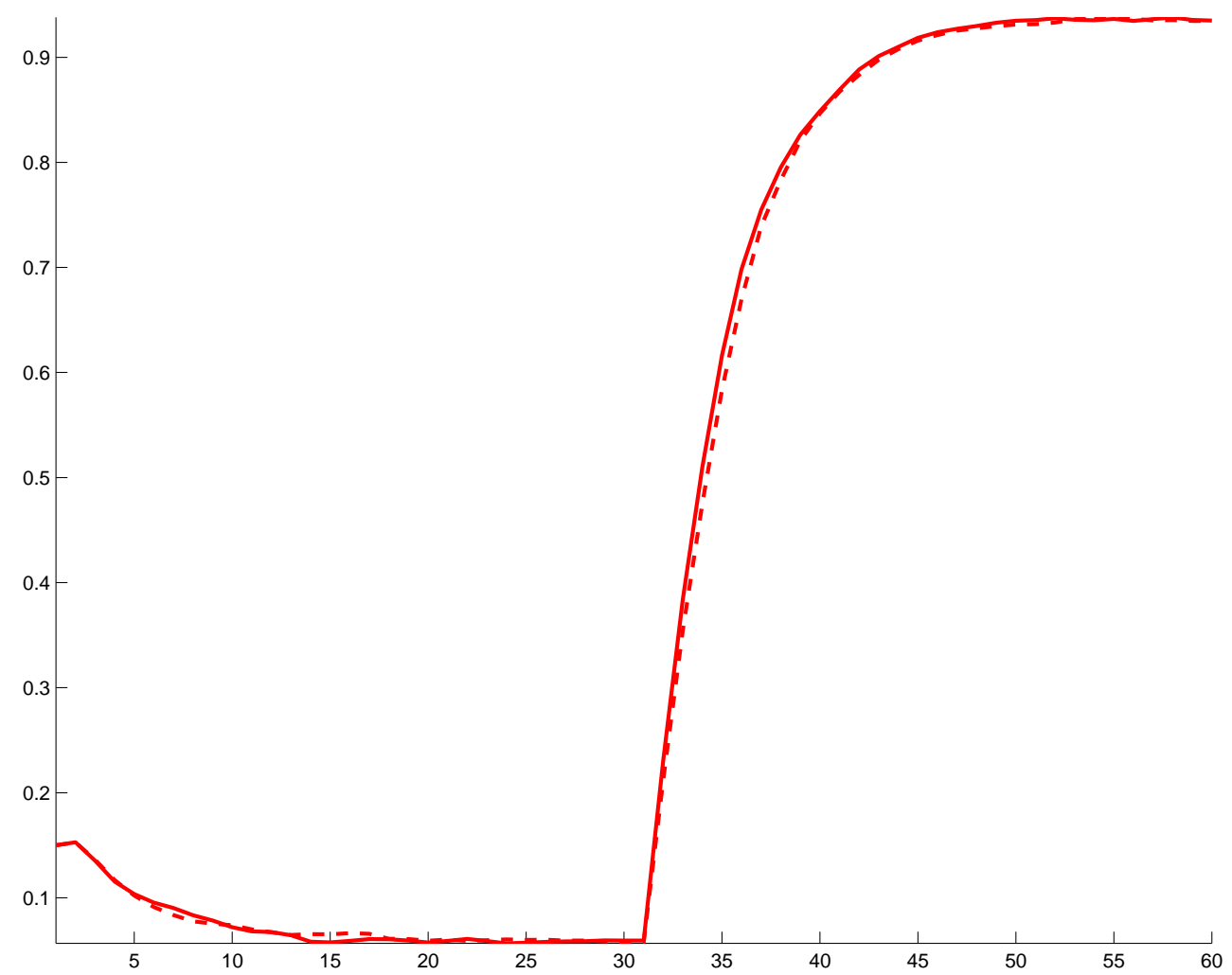

Figure 9: Prior Evolution with a change from the Balance Sheet model to the Textbook model in middle of sample. 


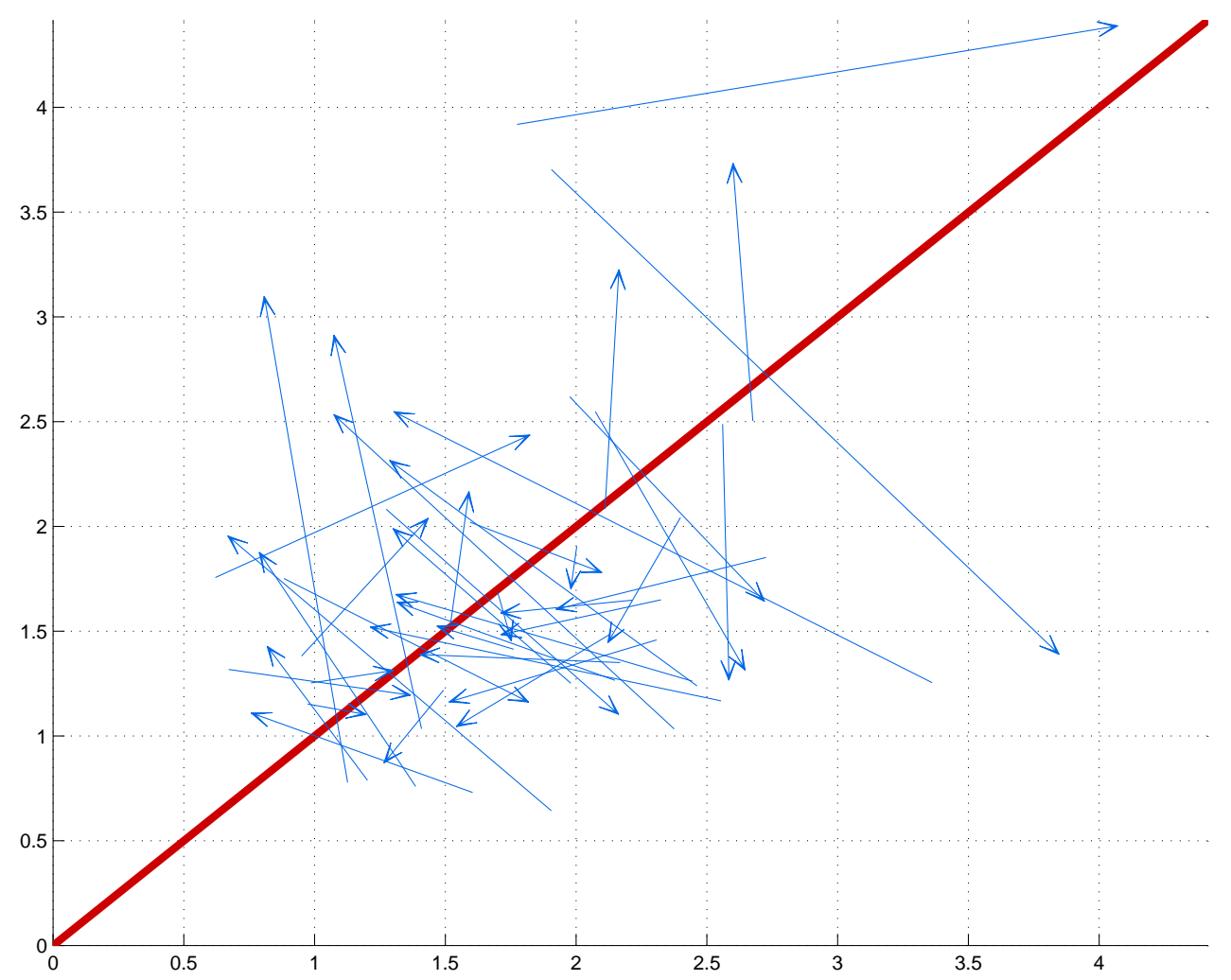

Figure 10: Simulation of Cross Country Evidence: The model is subject to a parameter change from the Balance Sheet model to the Textbook model in the early 2000's 


\section{Concluding Remarks}

This paper was motivated by a conversation between the Chairman of a Central Bank in a developing country and a member of his modeling unit:

-Econometrician: 'If you don't let it variate you'll never learn what its impact is'

-Central Banker: 'I don't want to learn'.

Indeed, this dialogue may have often occurred in various developing countries. Crosscountry data, on the other hand, seems to suggest that fear of floating was reduced in many of them during recent years. We tested the hypothesis that by believing in the balance sheet model, countries intervened substantially on their exchange rate markets and by this, they lost the ability to learn if the balance sheet model was indeed relevant for a long time.

We tested this hypothesis under Bayesian and robust optimal policies. The calibration suggests that the econometrician was wrong. Regardless of the fact that the exchange rate variations relative to output variations were low, a Bayesian or robust Central Bank would have discovered the true model in a shorter time than what the data seems to suggest. On the other hand, the model shows that the trend towards more flexible exchange rates could be explained if the structure of this economies changed. In particular, if the balance sheet structure of the economy was replaced by a classic textbook model. A parameter change of this type occurring between 1999 and 2003 could reconcile the model with the data. Behind the scenes, the finding suggests that the international currency crises of the late nineties bolstered reforms that made economies less prone to suffering from balance sheet mismatches. Our results lead us to ask what economic factors could have caused a systematic parameter change that has induced more flexibility in the exchange rates?

Though we would like to understand what could have caused a systematic parameter change, we are confident that, on their own, wrong beliefs cannot account for an international trend towards more flexible exchange rates. 


\section{References}

Adam, Klaus (2004), On the relation between robust and Bayesian decision making, Journal of Economic Dynamics and Control, Vol. 28, 2105 2117. 20

Aghion, P., P. Bacchetta, and A. Banerjee (2000), A simple model of monetary policy and currency crises, European Economic Review, Vol. 44, 728-738. 2, 11

Aghion, P., P. Bacchetta, and A. Banerjee (2001), Currency Crises and Monetary Policy in an Economy with Credit Constraints, European Economic Review, Vol. 45, 1121-50. 2

Aumann, R. (1979), Agreeing to Disagree, The Annals of Statistics, Vol. 4, No. 6, 1236-1239. 9

Ball, L. (1999), Policy Rules for Open Econoies, Monetary Policy Rules, University of Chicago Press, Chicago, IL. 6

Beck, Gunter W. and Volker Wieland (2002), Central bank misperceptions and the role of money in interest-rate rules, Journal of Monetary Economics, Vol. 55, S1S17.

Bigio, Saki and Marco Vega (2006), Optimal Monetary Policy under Balance Sheet Uncertainty, Mimeo. 8

Brainard, W. (1967), Uncertainty and the Effectiveness of Policy, American Economic Review, 57, Papers and Proceedings, 411-425. 2

Caballero, Ricardo J. and Arvind Krishnamurthy (2001), International and Domestic Collateral Constraints in a Model of Emerging Market Crises, Journal of Monetary Economics 48, 513-48. 2

Calvo, G. and C. Reinhart (2002), Fear of Floating, Quarterly Journal of Economics, 117, 379-408. 2, 4, 10

Cavallo, M., K. Kisselev, F. Perri and N. Roubini (2004), Exchange Rate Overshooting and the Costs of Floating, Mimeo, New York University.

Céspedes, L.F., R.Chang and A. Velasco(2002), Balance Sheets and Exchange Rate Policy, American Economic Review 94 (September) pp. 1183-1193. 2

Clarida R., J. Gali and M. Gertler(2001), Optimal Monetary Policy in Open versus Closed Economies: An Integrated Approach, American Economic Review Papers and Proceedings, Vol. 91, No. 2, 248-252. 2, 7 
Clarida R., J. Gali and M. Gertler(2001), A simple framework for international monetary policy analysis, Journal of Monetary Economics, Vol. 49, 879904. 7

Chang R. (1994), Endogenous Currency Substitution, Inflationary Finance and Welfare, Journal of Money Credit and Banking, Vol. 26, No. 4, 903-916.

Chang R. and A. Velasco(2000), Exchange Rate Policy for Developing Countries, The American Economic Review, Vol. 90, No. 2, 71-75. 5

Chang R. and A. Velasco (2004), Monetary Policy and the Currency Denomination of Debt: A Tale of Two Equilibria, Journal of International Economics, Vol. 69, 150-175. 2, 5

Chari, V. V., Patrick J. Kehoe, Ellen R. McGrattan (2002), Can Sticky Price Models Generate Volatile and Persistent Real Exchange Rates?, Review of Economic Studies Vol. 69, No. 3, 533-563. 13

Cogley, T. R. Colacito and T. Sargent(2007), Benefits from U.S. Monetary Policy Experimentation in the Days of Samuelson and Solow and Lucas, Journal of Money Credit Banking, . 3, 8

Cogley, T. R. Colacito, L. P. Hansen and T. Sargent(2008), Robustnes and U.S. Monetary Policy Experimentation, Mimeo . 3, 8, 17, 18

De Paoli, B. (2009), Monetary Policy and Welfare in a Small Open Economy, Journal of International Economics, Vol. 77, 11227

Ellison, M. (2006), The Learning Cost of Interest Rate Reversals, Journal of Monetary Economics, Vol. 53, 1895-1907 3, 9

Ellison, M., L. Sarno and J. Vilmunen (2007), Caution or Activism? Monetary Policy Strategies in an Open Economy, Macroeconomic Dynamics, Vol. 11, 519-541. 3

Frankel J.(2005), Contractionary Currency Crashes in Developing Countries, IMF Staff Papers, 52, No. 2. 2

Faia, E. and T. Monacelli (2008), Optimal monetary policy in a small open economy with home bias, Journal of Money, Credit and Banking Vol. 40, No. 4, 721750. 7

Gali, J. and T. Monacelli (2005), Monetary Policy and Exchange Rate Volatility in a Small Open Economy, Review of Economic Studies 72, No. 3, 707-734. 2, 6, 7

Goodhart C.(2005), The Future of Central Banking, FMG Special Paper No. 162. 5 
Hansen, L.P. and Sargent, T. J. (2006), Wanting Robustness in Macroeconomics, Working Paper. 3, 17

Hansen, L.P. and Sargent, T. J. (2007), Robustness, Princeton University Press, Princeton New Jersey. 3, 17

Hansen, L.P., T. J. Sargent, and T. D. Tallarini (1999), Robust Permanent Income and Pricing, Review of Economic Studies, Vol. 66, No. 4, 873-907. 20

Hausmann, R. Panizza, U, and Stein, E. (2001), Why do countries float the way they float?, Jorunal of Development Economics, 66, pp. 387-414. 2, 4

Ize, A. and E. Levy-Yeyati (2003), Fiancial Dollarization: Causes and Consequences, Journal of International Economics, Vol. 59, 323-347. 5

Kasa, K. (1999), Will the fed ever learn?, Journal of Macroeconomics, Vol. 21, No. 2, 279-292. 11

Krugman, P.(1999), Balance Sheets Effects, the Transfer Problem and Financial Crises, in Isard P., A. Razin and A.K. Rose, eds., International Finance and Financial Crises: Essays in Honour of Robert P. Flood, Jr., (New York: Kluwer Academic Publishers), pp. 31-44. 2

Lubik, T. A. and F. Schorfheide (2007), Journal of Monetary Economics, 54, pp. 1069-1087 $7,11,12$

Levy-Yeyati, E. and F. Sturzenegger (2003), To Float or to Fix: Evidence of the Impact of Exchange Rate Regimes on Economic Growth, The American Economic Review, Vol. 93, No. 4, 1173-1193. 5

Levy-Yeyati, E. and F. Sturzenegger (2003), Classifying Exchange Rate Regimes: Deeds vs. Words, European Economic Review, Vol. 49, No. 6, 1603-1635. 5

Monacelli, T. (2004), Into the Mussa Puzzle: Monetary Policy and the Real Exchange Rate in a Small Open Economy, Journal of International Economics, Vol. 62, 191-217.

Monacelli, T. (2005), Monetary Policy in a Low Pass-Through Enviornment, Journal of Money Credit and Banking, Vol. 37, N. 6. 1047-1066. 12

Murchison, S. and A. Rennison (2006), ToTEM: The Bank of Canadas New Quarterly Projection Model, Bank of Canada Technical Report No. 97. 11 
Schneider, M. and A. Tornell (2004), Balance Sheet Effects, Bailout Guarantees and Financial Crises, The Review of Economic Studies, Vol. 71, No. 3, pp. 883-913. 2

Wieland, Volker (2000), Learning by doing and the value of optimal experimentationOptimal learning with endogenous information, Journal of Economic Dynamics and Control Vol. 24, 501534. 3, 8

Wieland, Volker (2000b) Monetary policy, parameter uncertainty and optimal learning, Journal of Monetary Economics Vol. 46, 199228. 3, 8 


\section{A Optimal Discretionary Policy under Certainty}

[For referee's ease.]

The behavior of private agents described by equations 1, 2 and 3 can be reduced to a simple two-equation system by direct substitution. :

$$
\begin{gathered}
\pi_{t}=\beta E_{t}\left[\pi_{t+1}\right]+\gamma y_{t}+\varepsilon_{\pi, t} \\
y_{t}=E_{t}\left[y_{t+1}\right]-(\chi-\theta) i_{t}+\chi E_{t}\left[\pi_{t+1}\right]+\mu_{y, t}
\end{gathered}
$$

where we have replaced 3 into 2 and set $\mu_{y, t}=\chi r_{t}^{n}-\theta i_{t}^{*}-\theta \varepsilon_{e t}+\varepsilon_{y, t}$.

We use the Phillips curve to solve the minimization problem and the IS equation to infer the policy rate that implements the solution:

$$
\mathfrak{L}_{\tau}=E_{\tau}\left[\sum_{t=\tau}^{\infty} \beta^{t-\tau}\left\{\pi_{t}^{2}+w y_{t}^{2}+\lambda_{t}\left(\beta \pi_{t+1}+\gamma y_{t}+\varepsilon_{\pi, t}-\pi_{t}\right)\right\}\right]
$$

The discretionary solution implies that the following first-order conditions with respect to $E_{t}\left[\pi_{t}\right]$ and $E_{t}\left[y_{t}\right]$ holds every period ${ }^{20}$ :

$$
2 E_{t}\left[\pi_{t}\right]=E_{t}\left[\lambda_{t}\right]
$$

and

$$
2 w E_{t}\left[y_{t}\right]+\gamma E_{t}\left[\lambda_{t}\right]=0
$$

The two variables have to be steered using the relation:

$$
-\frac{\gamma}{w} E_{t}\left[\pi_{t}\right]=E_{t}\left[y_{t}\right]
$$

In order to implement this rule through the policy instrument $i_{t}$, we replace the above condition in the Phillips curve to obtain

$$
\left(1+\frac{\gamma^{2}}{w}\right) E_{t}\left[\pi_{t}\right]=\beta E_{\tau}\left[\pi_{t+1}\right]+\rho_{\pi} \varepsilon_{\pi, t-1}
$$

This equation can be solved by guessing a solution for the expectations operator $E_{t}\left[\pi_{t}\right]=$ $\Lambda \varepsilon_{\pi, t-1}$ where $\Lambda$ is parameter to be determined. This guess in turn implies $E_{t}\left[\pi_{t+1}\right]=$

\footnotetext{
${ }^{20}$ Implicitly we are assuming the Central Bank controls expectations directly.
} 
$\Lambda \rho_{\pi} \varepsilon_{\pi, t-1}$. Substituting the guess back into the Phillips curve allows us to obtain the solution to the unknown parameter $\Lambda$ :

$$
\Lambda=\frac{\rho_{\pi}}{1+\frac{\gamma^{2}}{w}-\beta \rho_{\pi}}
$$

Given expectations on the outcome, the interest rate can be backed out through the gap equation 12:

$$
i_{t}=\frac{1}{(\chi-\theta)}\left\{E_{t}\left[y_{t+1}\right]-E_{t}\left[y_{t}\right]+\chi E_{t}\left[\pi_{t+1}\right]+E_{t}\left[\mu_{y, t}\right]\right\}
$$

so replacing our initial guess into this functional leads to:

$$
i_{t}=\frac{1}{(\chi-\theta)}\left\{\left(\frac{\gamma}{w}\left(\frac{1}{\rho_{\pi}}-1\right)+\chi\right) \Lambda \rho_{\pi} \varepsilon_{\pi, \tau-1}+E_{t}\left[\mu_{y, t}\right]\right\}
$$

This completes the proof of the optimal policy in the perfect certainty case.

For the special case of $\rho_{\pi} \rightarrow 0$ we have that

$$
i_{t} \rightarrow \frac{1}{(\chi-\theta)} E_{t}\left[\mu_{y, t}\right]
$$

which is a simple rule that attains zero inflation by reacting to observed shock to the output gap.

Giving the timing protocol, the solution to the expectation of exogenous shocks is:

$$
E_{t}\left[\mu_{y, t}\right]=\chi\left(\rho_{r} \varepsilon_{r, t-1}\right)-\theta \varepsilon_{i, t}-\theta \varepsilon_{e, t}+\rho_{y, t} \varepsilon_{y, t-1}
$$

where the expectation takes that form given the assumption that $\varepsilon_{e t}$ and $\varepsilon_{i, t}$ are observable.

We then substitute this result 12 and obtain:

$$
y_{t}=E_{t}\left[y_{t+1}\right]-\left(\frac{\gamma}{w}\left(\frac{1}{\rho_{\pi}}-1\right)+\chi\right) \Lambda \rho_{\pi} \varepsilon_{\pi, \tau-1}+\chi E_{t}\left[\pi_{t+1}\right]+\mu_{y, t}-E_{t}\left[\mu_{y, t}\right]
$$

with initial guess this equation further simplifies to:

$$
y_{t}=-\frac{\gamma}{w} \Lambda \varepsilon_{\pi, \tau-1}+\mu_{y, t}-E_{t}\left[\mu_{y, t}\right]
$$

This confirms our guess for the law of motion $y_{t}$ 's expectation.

In terms of the primitives we obtain:

$$
y_{t}=-\frac{\gamma}{w} \Lambda \varepsilon_{\pi, \tau-1}+\chi \nu_{r, t}+\nu_{y, t}
$$


To determine the law of motion of inflation from 11:

$$
\begin{aligned}
\pi_{t} & =\beta \Lambda \rho_{\pi} \varepsilon_{\pi, t-1}+\gamma\left(-\frac{\gamma}{w} \Lambda \varepsilon_{\pi, \tau-1}+\chi \nu_{r, t}+\nu_{y, t}\right)+\varepsilon_{\pi, t} \\
& =\Lambda\left(\beta \rho_{\pi}-\frac{\gamma^{2}}{w}\right) \varepsilon_{\pi, t-1}+\gamma \chi \nu_{r, t}+\gamma \nu_{y, t}+\rho_{p} \varepsilon_{\pi, t-1}+\nu_{\pi, t}
\end{aligned}
$$

so synthesizing:

$$
\pi_{t}=\left((\Lambda \beta+1) \rho_{\pi}-\frac{\gamma^{2}}{w} \Lambda\right) \varepsilon_{\pi, t-1}+\gamma \chi \nu_{r, t}+\gamma \nu_{y, t}+\nu_{\pi, t}
$$

The value of the exchange rate is obtained directly from the UIP equation 3 :

$$
E_{t}\left[\triangle s_{t+1}\right]=i_{t}-i_{t}^{*}-\varepsilon_{e t}
$$

\section{A.1 Steady State of the Economy}

In absence of shocks we obtain from 16 the steady state value of the interest rate, $\bar{\imath}$, in terms of the steady state of the stochastic process, $\bar{\mu}_{y, t}$, and inflation, $\bar{\pi}_{t}$. The steady state for the stochastic process is:

$$
\bar{\mu}_{y}=\chi \bar{r}+\theta \bar{\imath}^{*}
$$

so

$$
\bar{\imath}=\frac{1}{(\chi-\theta)}\left[\bar{\mu}_{y}\right]
$$

so from the steady state version of the Phillips curve and the gap condition we obtain:

$$
0=-(\chi-\theta) \bar{\imath}+\chi \bar{\pi}+\bar{\mu}_{y}
$$

which in turn implies: $\bar{\pi}=0$.

The non-commitment policy yields the desired result of $\bar{y}=0$. Thus, in absence of shocks, the policy induces the highest lowest cost possible. 


\section{A.2 State-Space Representation}

\section{A.2.1 Exogenous State Block}

The exogenous state vector-equation for this model is:

$$
S_{t}=A S_{t-1}+B w_{t}
$$

were explicitly it is expressed in matrix notation matching our paramors according to :

$$
\begin{gathered}
{\left[\begin{array}{c}
\varepsilon_{\pi, t} \\
\varepsilon_{\pi, t-1} \\
\varepsilon_{y, t} \\
\varepsilon_{y, t-1} \\
r_{t}^{n} \\
r_{t-1}^{n} \\
i_{t}^{*} \\
\varepsilon_{e, t} \\
1
\end{array}\right]=\left[\begin{array}{ccccccccc}
\rho_{\pi} & 0 & 0 & 0 & 0 & 0 & 0 & 0 & 0 \\
1 & 0 & 0 & 0 & 0 & 0 & 0 & 0 & 0 \\
0 & 0 & \rho_{y} & 0 & 0 & 0 & 0 & 0 & 0 \\
0 & 0 & 1 & 0 & 0 & 0 & 0 & 0 & 0 \\
0 & 0 & 0 & 0 & \rho_{r} & 0 & 0 & 0 & r^{n} \\
0 & 0 & 0 & 0 & 1 & 0 & 0 & 0 & 0 \\
0 & 0 & 0 & 0 & 0 & 0 & \rho_{i} & 0 & r^{n} \\
0 & 0 & 0 & 0 & 0 & 0 & 0 & \rho_{e} & 0 \\
0 & 0 & 0 & 0 & 0 & 0 & 0 & 0 & 1
\end{array}\right]\left[\begin{array}{c}
\varepsilon_{\pi, t-1} \\
\varepsilon_{\pi, t-2} \\
\varepsilon_{y, t-1} \\
\varepsilon_{y, t-2} \\
r_{t-1}^{n} \\
r_{t-2}^{n} \\
i_{t-1}^{*} \\
\varepsilon_{e, t-1} \\
1
\end{array}\right]} \\
+\left[\begin{array}{cccccc|c}
\sigma_{\pi} & 0 & 0 & 0 & 0 \\
0 & 0 & 0 & 0 & 0 \\
0 & \sigma_{y} & 0 & 0 & 0 \\
0 & 0 & 0 & 0 & 0 \\
0 & 0 & \sigma_{r} & 0 & 0 \\
0 & 0 & 0 & 0 & 0 \\
0 & 0 & 0 & \sigma_{i} & 0 \\
0 & 0 & 0 & 0 & \sigma_{e} \\
0 & 0 & 0 & 0 & 0
\end{array}\right] \\
\nu_{r, t} \\
\nu_{s, t+1}
\end{gathered}
$$

Recall we adopt, by expositional motives, the convention that $i_{t}^{*}=\varepsilon_{i, t}$.

\section{A.2.2 Observable State Equation}

The observable vector-equation for this model is:

$$
Z_{t}=C S_{t}+D u_{t}
$$

we use the following parameters auxiliaries to find a parsimony representation. 
Policy Rule: For the policy reaction we can define the following set of auxiliary parameters:

$$
\begin{gathered}
F_{1}=\frac{1}{(\chi-\theta)}\left(\frac{\gamma}{w}\left(\frac{1}{\rho_{\pi}}-1\right)+\chi\right) \Lambda \rho_{\pi} \\
F_{2}=\frac{1}{(\chi-\theta)} \rho_{y, t} \\
F_{3}=\frac{1}{(\chi-\theta)} \chi \rho_{r} \\
F_{4}=-\frac{1}{(\chi-\theta)} \theta \\
F_{5}=-\frac{1}{(\chi-\theta)} \theta
\end{gathered}
$$

and we have that:

$$
i_{t}=F_{1} \varepsilon_{\pi, t-1}+F_{2} \varepsilon_{y, t-1}+F_{3} \varepsilon_{r, t-1}+F_{4} \varepsilon_{i, t}+F_{5} \varepsilon_{e, t}
$$

Phillips Curve: Redefining 19 we obtain that:

$$
\pi_{t}=\left((\Lambda \beta+1) \rho_{\pi}-\frac{\gamma^{2}}{w} \Lambda\right) \varepsilon_{\pi, t-1}+\gamma \chi\left(r_{t}^{n}-\rho_{r} r_{t-1}^{n}\right)+\gamma\left(\varepsilon_{y, t}-\rho_{y} \varepsilon_{y, t-1}\right)+\left(\varepsilon_{\pi, t}-\rho_{\pi} \varepsilon_{\pi, t-1}\right)
$$

and using the auxiliaries:

$$
\begin{aligned}
G_{1} & =1 \\
G_{2} & =\Lambda\left(\beta-\frac{\gamma}{w}^{2}\right) \\
G_{3} & =\gamma \\
G_{4} & =-\gamma \rho_{y} \\
G_{5} & =\gamma \chi \\
G_{6} & =-\gamma \chi \rho_{r}
\end{aligned}
$$

Output Gap: Recall that we can summarize the output gap by equation 18 so regrouping it we obtain:

$$
y_{t}=-\frac{\gamma}{w} \Lambda \varepsilon_{\pi, \tau-1}+\chi\left(r_{t}^{n}-\rho_{r} r_{t-1}^{n}\right)+\varepsilon_{y, t}-\rho_{y} \varepsilon_{y, t-1}
$$

so we define the following auxiliary variables: 


$$
\begin{aligned}
H_{1} & =-\frac{\gamma}{w} \Lambda \\
H_{2} & =1 \\
H_{3} & =-\rho_{y} \\
H_{4} & =\chi \\
H_{5} & =-\chi \rho_{r}
\end{aligned}
$$

Nominal Depreciation and Final Matrix form We are looking for a system of the sort:

$$
Z_{t}=C S_{t}
$$

To obtain this matrix equation we can write this by using 20 and noting that it can be written as a function of the exogenous processes that affect the policy instrument and the observable shocks that affect these equation directly. Summing up, the matrix form for the set of observable should look like:

$$
\left[\begin{array}{c}
i_{t} \\
\pi_{t} \\
y_{t}\left[\Delta s_{t+1}\right]
\end{array}\right]=\left[\begin{array}{ccccccccc}
0 & F_{1} & 0 & F_{2} & 0 & F_{3} & F_{4} & F_{5} & 0 \\
G_{1} & G_{2} & G_{3} & G_{4} & G_{5} & G_{6} & 0 & 0 & 0 \\
0 & H_{1} & H_{2} & H_{3} & H_{4} & H_{5} & 0 & 0 & 0 \\
0 & F_{1} & 0 & F_{2} & 0 & F_{3} & F_{4}-1 & F_{5}-1 & 0
\end{array}\right]\left[\begin{array}{c}
\varepsilon_{\pi, t} \\
\varepsilon_{\pi, t-1} \\
\varepsilon_{y, t} \\
\varepsilon_{y, t-1} \\
r_{t}^{n} \\
r_{t-1}^{n} \\
i_{t}^{*} \\
\varepsilon_{e, t} \\
1
\end{array}\right]
$$




\section{B Solution to the Passive Learning Policy without Com- mitment under Uncertainty}

This appendix describes the solution to the Central Bank's problem when he behaves as a Bayesian optimizer.

\section{B.1 Setting up the Lagrangian}

We solve the central bank problem without commitment under model uncertainty following similar procedures as we use for the case with model certainty. The main difference corresponds to the way in which agents agent's and the Central Bank form their expectations.

Hence, the objective is to solve for the following, prior-conditional Lagrangian:

$$
\mathfrak{L}_{\tau}\left(p_{\tau}\right)=L_{\tau}\left(p_{\tau}\right)+\sum_{t=\tau}^{\infty} \lambda_{t} \beta^{t} E_{t}\left[\left(\pi_{t+1}+\gamma_{y} y_{t}+\varepsilon_{\pi}-\pi_{t}\right) \mid p_{t}\right]
$$

so the first order conditions with respect to $\left\{\pi_{t}\right\}_{t=\tau}^{\infty}$ and $\left\{y_{t}\right\}_{t=\tau}^{\infty}$ is the same as in the case with model certainty, except for the fact that expectations take the prior in consideration. Recall from section 3 that agent expectations and the central bank's expectations on inflation regarding the prior are the same by assumption. This assumption allows us to regroup the expectation operator of the Central Bank as well as the agents expectations present in the Phillips curve. The Bayesian counterpart of 13 is:

$$
-\frac{\gamma}{w} E_{t}\left[\pi_{t} \mid p_{t}\right]=E_{t}\left[y_{t} \mid p_{t}\right]
$$

We can apply the expectations operator conditional on the prior to the Phillips curve and obtain a counterpart to 14 :

$$
\left(1+\frac{\gamma}{w}\right) E_{t}\left(\pi_{t} \mid p_{t}\right)=\beta E_{t}\left(\pi_{t+1} \mid p_{t}\right)+\rho_{\pi} \varepsilon_{\pi, t-1}
$$

The main complication here is how to deal with the conditional expectations $E_{\tau}\left(\pi_{\tau+1} \mid p_{t}\right)$. Again we take the guess of a linear functional in terms of the previous shocks. We use a linear combination of both these shocks to make a guess:

$$
E_{\tau}\left(\pi_{t} \mid p_{t}\right)=\Lambda^{B A Y} \rho_{\pi} \varepsilon_{\pi, t-1}
$$

where $\Lambda^{B A Y}$ is the parameter yet to be determined.

The solution to $\Lambda^{B A Y}$ is the same as for 15 : 


$$
\Lambda^{B A Y}=\frac{\rho_{\pi}}{1+\frac{\gamma^{2}}{w}-\beta \rho_{\pi}}
$$

this is the same result as the one obtained in the Perfect Certainty case. Thus, the intuition behind this result is that the Central Banks goal is the same both, under certainty and uncertainty and given what he knows he will try to maintain inflation as if he knew the true model. Consequently, regardless of the definition of expectations, the Central Bank will try to set these expectations to the same number. The difference will be in the action he takes.

The law of motion for $\left\{E_{\tau}\left(\pi_{t} \mid p_{t}\right)\right\}_{t=\tau}^{\infty}$ will be an analog to the perfect certainty case and thus:

$$
E_{\tau}\left[\pi_{t} \mid p_{t}\right]=\Lambda^{B A Y} \rho_{\pi}^{t+1-\tau} \varepsilon_{\pi, \tau-1}
$$

Having sorted out what $\left\{E_{\tau}\left(\pi_{t}\right)\right\}_{t=\tau}^{\infty}$ is we may obtain the corresponding expected path for $\left\{E_{\tau}\left(y_{t}\right)\right\}_{t=\tau}^{\infty}$ with the use of 12 :

$$
E_{\tau}\left[y_{t}\right]=-\frac{\gamma_{y}}{w} E_{\tau}\left[\pi_{t}\right]
$$

We obtain the result for the optimal no-commitment policy by taking the Bayesian expectation in the aggregate demand equation 12 and clearing out the interest rate:

$$
i_{\tau}^{B A Y}=\frac{1}{\Psi\left(p_{t}\right)}\left[E_{\tau}\left(y_{\tau+1}-y_{\tau} \mid p_{t}\right)+\chi E_{\tau}\left(\pi_{\tau+1} \mid p_{t}\right)+E_{\tau}\left(\mu_{y, \tau} \mid p_{t}\right)\right]
$$

where $\Psi\left(p_{t}\right)=\chi-\left(p_{t} \theta^{H}+\left(1-p_{t}\right) \theta^{L}\right)$

Replacing the previous results we obtain a similar result as before:

$$
i_{\tau}^{B A Y}=\frac{1}{\Psi\left(p_{t}\right)}\left[\left(\chi+\frac{\gamma_{y}}{w}\left(\frac{1}{\rho_{\pi}}-1\right)\right) \Lambda \rho_{\pi} \varepsilon_{\pi, \tau-1}+E_{\tau}\left(\mu_{y, \tau} \mid p_{t}\right)\right]
$$

For the special case of $\rho_{\pi}=0$ we have that

$$
i_{t}^{B A Y}=\frac{1}{\Psi\left(p_{t}\right)} E_{t}\left[\mu_{y, t} \mid p_{t}\right]
$$

which is a simple rule that reacts to only to the shocks that affect the output gap. Given the data set available at $\tau, E_{\tau}\left(\mu_{y, \tau} \mid p_{t}\right)$ may be easily computed by taking the weighted average of the shocks that affect the model. Notice that $\varepsilon_{y, t-1}$ is not identified and depends on the model as it is obtained as a residual to the output gap equation, which in the end depends on the parameter on which we have uncertainty about. 


\section{B.2 State Space Representation}

\section{B.2.1 Exogenous State Block}

The exogenous state vector-equation for this model is:

$$
S_{t}=A\left(p_{t}\right) S_{t-1}+B w_{t}
$$

were explicitly it is expressed in matrix notation matching our parameters according to :

$$
\begin{gathered}
{\left[\begin{array}{c}
\varepsilon_{\pi, t} \\
\varepsilon_{\pi, t-1} \\
\varepsilon_{y, t} \\
\varepsilon_{y, t-1} \\
r_{t}^{n} \\
r_{t-1}^{n} \\
i_{t}^{*} \\
\varepsilon_{e, t} \\
1 \\
\tilde{\varepsilon}_{y, t} \\
\tilde{\varepsilon}_{y, t-1}
\end{array}\right]=\left[\begin{array}{ccccccccccc}
\rho_{\pi} & 0 & 0 & 0 & 0 & 0 & 0 & 0 & 0 & 0 & 0 \\
1 & 0 & 0 & 0 & 0 & 0 & 0 & 0 & 0 & 0 & 0 \\
0 & 0 & \rho_{y} & 0 & 0 & 0 & 0 & 0 & 0 & 0 & 0 \\
0 & 0 & 1 & 0 & 0 & 0 & 0 & 0 & 0 & 0 & 0 \\
0 & 0 & 0 & 0 & \rho_{r} & 0 & 0 & 0 & r^{n} & 0 & 0 \\
0 & 0 & 0 & 0 & 1 & 0 & 0 & 0 & 0 & 0 & 0 \\
0 & 0 & 0 & 0 & 0 & 0 & \rho_{i} & 0 & r^{n} & 0 & 0 \\
0 & 0 & 0 & 0 & 0 & 0 & 0 & \rho_{e} & 0 & 0 & 0 \\
0 & 0 & 0 & 0 & 0 & 0 & 0 & 0 & 1 & 0 & 0 \\
J_{1} & 0 & J_{2} & 0 & J_{3} & 0 & J_{4} & J_{5} & 0 & J_{6} & 0 \\
0 & 0 & 1 & 0 & 0 & 0 & 0 & 0 & 0 & 0 & 0
\end{array}\right]\left[\begin{array}{c}
\varepsilon_{\pi, t-1} \\
\varepsilon_{\pi, t-2} \\
\varepsilon_{y, t-1} \\
\varepsilon_{y, t-2} \\
r_{t-1}^{n} \\
r_{t-2}^{n} \\
i_{t-1}^{*} \\
\varepsilon_{e, t-1} \\
1 \\
\tilde{\varepsilon}_{y, t-1} \\
\tilde{\varepsilon}_{y, t-2}
\end{array}\right]} \\
\left.+\left[\begin{array}{cccccc|ccc}
\sigma_{\pi} & 0 & 0 & 0 & 0 \\
0 & 0 & 0 & 0 & 0 \\
0 & \sigma_{y} & 0 & 0 & 0 \\
0 & 0 & 0 & 0 & 0 \\
0 & 0 & \sigma_{r} & 0 & 0 \\
0 & 0 & 0 & 0 & 0 \\
0 & 0 & 0 & \sigma_{i} & 0 \\
0 & 0 & 0 & 0 & \sigma_{e} \\
0 & 0 & 0 & 0 & 0 \\
J_{7} & 0 & 0 & J_{8} & J_{9} \\
0 & 0 & 0 & 0 & 0
\end{array}\right] \begin{array}{llll}
\nu_{\pi, t} \\
\nu_{y, t}
\end{array}\right] \\
\nu_{i, t} \\
\nu_{s, t}
\end{gathered}
$$

Recall that as in the previous section, we adopt for expositional motives, the convention that $i_{t}^{*}=\varepsilon_{i, t}$. As opposed to the system that we defined in the previous appendix. we have introduced to extra columns. The columns refer to the residual of the false model that will be an endogenous outcome of the model. Note that we have not yet solved for the unknowns 
$\left\{J_{s}\right\}_{s=1}^{9}$. To do so, we will use a result from the next section.

\section{B.2.2 Endogenous State Block}

Take the policy reaction function describe in equation 23 and our guess for the formation of expectations and replace this results correspondingly in the equation 12 for each of the models. Assume that $\theta^{T}$ is the true value and $\theta^{F}$ the false value. We will obtain that the output gap will be:

$$
y_{t}=\left(\chi-\frac{\gamma}{w}\right) \Lambda^{B A Y} \rho_{\pi} \varepsilon_{\pi, t-1}-\left(\chi-\theta^{T}\right) i_{t}+\mu_{y, t}
$$

and the according outcome of the misspecified model would be:

$$
\tilde{y}_{t}=\left(\chi-\frac{\gamma}{w}\right) \Lambda^{B A Y} \rho_{\pi} \varepsilon_{\pi, t-1}-\left(\chi-\theta^{F}\right) i_{t}+\tilde{\mu}_{y, t}
$$

The term in the variables of this equation are the outcomes of under the false model. For the same observation $y_{t}$, each model implies a different innovation. To obtain the false model's output gap residual as a function of the innovations to the true model we subtract both equations and equate the left hand side to 0 .

$$
\mu_{y, t}+\left(\theta^{T}-\theta^{F}\right) i_{t}-\tilde{\mu}_{y, t}=0
$$

We now use the definition of both terms and find that:

$$
\varepsilon_{y, t}+\left(\theta^{T}-\theta^{F}\right) i_{t}=\tilde{\varepsilon}_{y, t}
$$

which in turn implies that:

$$
\rho \varepsilon_{y, t-1}+v_{y, t}+\left(\theta^{T}-\theta^{F}\right) i_{t}=\rho_{y} \tilde{\varepsilon}_{y, t-1}+\tilde{v}_{y, t}
$$

Recall that $\varepsilon_{y, t-1}$ and $\tilde{\varepsilon}_{y, t-1}$ are state variables for the Central Bank. Then, $\tilde{v}_{y, t}$ is an endogenous outcome of the model. To obtain an explicit solution to the we rely obtain a linear form of the Central Bank's Policy as a function of the innovations to the system.

Interest Rate: Recall the solution to the optimal policy 23 that:

$$
i_{\tau}^{B A Y}=\frac{1}{\Psi\left(p_{t}\right)}\left[\left(\chi+\frac{\gamma_{y}}{w}\left(\frac{1}{\rho_{\pi}}-1\right)\right) \Lambda \rho_{\pi} \varepsilon_{\pi, \tau-1}+E_{\tau}\left(\mu_{y, \tau} \mid p_{t}\right)\right]
$$

For the policy reaction we can define the following set of auxiliary parameters: 


$$
\begin{gathered}
F_{1}\left(p_{t}\right)=\frac{1}{\Psi\left(p_{t}\right)}\left(\frac{\gamma}{w}\left(\frac{1}{\rho_{\pi}}-1\right)-\chi\right) \Lambda \rho_{\pi} \\
F_{2}\left(p_{t}\right)=\frac{1}{\Psi\left(p_{t}\right)}\left(p_{t}\right) \rho_{y, t} \\
F_{3}\left(p_{t}\right)=\frac{1}{\Psi\left(p_{t}\right)} \chi \rho_{r} \\
F_{4}\left(p_{t}\right)=-\frac{1}{\Psi\left(p_{t}\right)}\left(p_{t} \theta^{T}+\left(1-p_{t}\right) \theta^{F}\right) \\
F_{5}\left(p_{t}\right)=-\frac{1}{\Psi\left(p_{t}\right)}\left(p_{t} \theta^{T}+\left(1-p_{t}\right) \theta^{F}\right) \\
F_{6}\left(p_{t}\right)=\frac{1}{\Psi\left(p_{t}\right)}\left(1-p_{t}\right) \rho_{y, t}
\end{gathered}
$$

and we have that:

$$
i_{t}=F_{1} \varepsilon_{\pi, t-1}+F_{2} \varepsilon_{y, t-1}+F_{3} \varepsilon_{r, t-1}+F_{4} \varepsilon_{i, t}+F_{5} \varepsilon_{e, t}+F_{6} \tilde{\varepsilon}_{y, t-1}
$$

Replacing this result in 25 allows us to compute the value of the $\left\{J_{s}\right\}_{s=1}^{5}$ since we can regroup this terms to obtain the value of $\tilde{v}_{y, t}$ and simply add the to the corresponding row of the evolution of the exogenous matrixes. We obtain the following result:

$$
\begin{aligned}
\tilde{v}_{y, t}= & \rho \varepsilon_{y, t-1}+v_{y, t}+\left(\theta^{T}-\theta^{F}\right) i_{t}-\rho_{y} \tilde{\varepsilon}_{y, t-1} \\
= & \left(\theta^{T}-\theta^{F}\right) F_{1} \varepsilon_{\pi, t-1}+\left(\left(\theta^{T}-\theta^{F}\right) F_{2}+\rho\right) \varepsilon_{y, t-1}+\left(\theta^{T}-\theta^{F}\right) F_{3} \varepsilon_{r, t-1} \\
& +\left(\theta^{T}-\theta^{F}\right) F_{4} \rho_{i} \varepsilon_{i, t-1}+\left(\theta^{T}-\theta^{F}\right) F_{5} \rho_{e} \varepsilon_{e, t-1}+\left(\left(\theta^{T}-\theta^{F}\right) F_{6}-\rho_{y}\right) \tilde{\varepsilon}_{y, t-1} \\
& +v_{y, t}+\left(\theta^{T}-\theta^{F}\right) F_{4} \nu_{i, t}+\left(\theta^{T}-\theta^{F}\right) F_{5} \nu_{e, t}
\end{aligned}
$$

Therefore we summarize this equation by:

$$
\tilde{\varepsilon}_{y, t}=J_{1} \varepsilon_{\pi, t-1}+J_{2} \varepsilon_{y, t-1}+J_{3} \varepsilon_{r, t-1}+J_{4} \varepsilon_{i, t-1}+J_{5} \varepsilon_{e, t-1}+J_{6} \tilde{\varepsilon}_{y, t-1}+J_{7} v_{y, t}+J_{8} \nu_{i, t}+J_{8} \nu_{e, t}
$$

Where the solution to: 


$$
\begin{aligned}
& J_{1}=\left(\theta^{T}-\theta^{F}\right) F_{1} \\
& J_{2}=\left(\left(\theta^{T}-\theta^{F}\right) F_{2}+\rho_{y}\right) \\
& J_{3}=\left(\theta^{T}-\theta^{F}\right) F_{3} \\
& J_{4}=\left(\theta^{T}-\theta^{F}\right) F_{4} \rho_{i} \\
& J_{5}=\left(\theta^{T}-\theta^{F}\right) F_{5} \rho_{e} \\
& J_{6}=\left(\theta^{T}-\theta^{F}\right) F_{6} \\
& J_{7}=1 \\
& J_{8}=\left(\theta^{T}-\theta^{F}\right) F_{4} \\
& J_{9}=\left(\theta^{T}-\theta^{F}\right) F_{5}
\end{aligned}
$$

Not that because the terms $\varepsilon_{r, t-1}$ and $\varepsilon_{i, t-1}$ don't have a zero mean, a priori we can expect the wrong model to have a bias (unless $\theta^{T}=\theta^{F}$ are trivially equal) whichever that is.

Inflation Equation We can use equation 19 proceed in the same manner as in Appendix (A) so the set $\left\{G_{s}\right\}_{s=\pi, y, r, i, e}$ remains the same.

Output Gap Equation The output gap's matrix form is obtained from equation 18 so we have:

$$
y_{t}=\left(\chi-\frac{\gamma}{w}\right) \Lambda^{B A Y} \rho_{\pi} \varepsilon_{\pi, t-1}-(\chi-\theta) i_{t}+\chi r_{t}^{n}-\theta i_{t}^{*}-\theta \varepsilon_{e t}+\varepsilon_{y, t}
$$

So use the following auxiliary variables:

$$
\begin{aligned}
& H_{1}\left(p_{t}\right)=\left(\chi-\frac{\gamma}{w}\right) \Lambda^{B A Y} \rho_{\pi}-\left(\chi-\theta^{T}\right) F_{1}\left(p_{t}\right) \\
& H_{2}\left(p_{t}\right)=1 \\
& H_{3}\left(p_{t}\right)=-\left(\chi-\theta^{T}\right) F_{2}\left(p_{t}\right) \\
& H_{4}\left(p_{t}\right)=\chi \\
& H_{5}\left(p_{t}\right)=-\left(\chi-\theta^{T}\right) F_{3} \\
& H_{6}\left(p_{t}\right)=-\theta^{T}-\left(\chi-\theta^{T}\right) F_{4} \\
& H_{7}\left(p_{t}\right)=-\theta^{T}-\left(\chi-\theta^{T}\right) F_{5} \\
& H_{8}\left(p_{t}\right)=-\left(\chi-\theta^{T}\right) F_{6}
\end{aligned}
$$


Nominal Depreciation and Matrix form Nominal Depreciations equation remains the same. Therefore, the system that summarize the economy takes the form:

$$
Z_{t}=C\left(p_{t}\right) S_{t}
$$

where the difference in relation to the result in $(A)$ is the appearance of parameter $p_{t}$.

Summing up, we can rewrite it as:

$$
\left[\begin{array}{c}
i_{t} \\
\pi_{t} \\
y_{t} \\
E\left[\Delta s_{t+1}\right]
\end{array}\right]=\left[\begin{array}{ccccccccccc}
0 & F_{1} & 0 & F_{2} & 0 & F_{3} & F_{4} & F_{5} & 0 & 0 & F_{6} \\
G_{1} & G_{2} & G_{3} & G_{4} & G_{5} & G_{6} & 0 & 0 & 0 & 0 & 0 \\
0 & H_{1} & H_{2} & H_{3} & H_{4} & H_{5} & H_{6} & H_{7} & 0 & 0 & H_{8} \\
0 & F_{1} & 0 & F_{2} & 0 & F_{3} & F_{4}-1 & F_{5}-1 & 0 & 0 & 0
\end{array}\right]\left[\begin{array}{c}
\varepsilon_{\pi, t} \\
\varepsilon_{\pi, t-1} \\
\varepsilon_{y, t} \\
\varepsilon_{y, t-1} \\
r_{t}^{n} \\
r_{t-1}^{n} \\
i_{t}^{*} \\
\varepsilon_{e, t} \\
1 \\
\tilde{\varepsilon}_{y, t} \\
\tilde{\varepsilon}_{y, t-1}
\end{array}\right]
$$

\section{B.3 Conditional Moments and Loss Functions}

Unconditional moments may be obtained via numerical simulations of the system above described. On the contrary, we can use the matrix forms in the above section here to obtain an analytical expression though not in close form solution. The system is summarized by to blocks of linear equations and a single non-linear equation computed

$$
\begin{gathered}
S_{t}=A\left(p_{t}\right) S_{t-1}+B w_{t} \\
Z_{t}=C\left(p_{t}\right) S_{t}
\end{gathered}
$$

and Bayes's updating rule.

$$
p_{t+1}=\frac{p_{t} P\left(\text { Data }_{t} \mid \text { Data }_{t-1}, M^{A}\right)}{p_{t} P\left(\text { Data }_{t} \mid \text { Data }_{t-1}, M^{A}\right)+\left(1-p_{t}\right) P\left(\text { Data }_{t} \mid \text { Data }_{t-1}, M^{B}\right)}
$$

Cogley et al. (2005) have shown that $p_{t+1}$ is a martingale. Conditional on the true model, we showed that $p_{t+1}$ is either a supermartingale or sub-martingale depending on which is the true model. We use this facts in the following section. 


\section{B.3.1 Moments Conditional on the True Model and State}

First Moments Conditional expectations over the exogenous states are:

$$
E_{t}\left[S_{t+1} \mid S_{t}, p_{t+1}\right]=A\left(p_{t+1}\right) S_{t}
$$

Substituting thin into the observable yields:

$$
E_{t}\left[Z_{t+1} \mid S_{t}, p_{t+1}\right]=C\left(p_{t+1}\right)\left[A\left(p_{t+1}\right)\right] S_{t}
$$

where for simplicity we defined:

$$
M\left(p_{t+1}\right)=C\left(p_{t+1}\right)\left[A\left(p_{t+1}\right)\right]
$$

Second Moments Recall the following equivalence:

$$
S_{t+1}=A\left(p_{t+1}\right) S_{t}+B w_{t+1}
$$

and therefore:

$$
Z_{t+1}=C\left(p_{t+1}\right)\left[A\left(p_{t+1}\right) S_{t}+B w_{t+1}\right]
$$

The loss at period $t+1$ is:

$$
Z_{t+1}^{\prime} W Z_{t+1}
$$

where

$$
W=\left[\begin{array}{cccc}
0 & 0 & 0 & 0 \\
0 & 1 & 0 & 0 \\
0 & 0 & w & 0 \\
0 & 0 & 0 & 0
\end{array}\right]
$$

We can substitute in the components of $Z_{t+1}$ to obtain:

$$
\left[A\left(p_{t+1}\right) S_{t}+B w_{t+1}\right]^{\prime} C\left(p_{t+1}\right)^{\prime} W C\left(p_{t+1}\right)\left[A\left(p_{t+1}\right) S_{t}+B w_{t+1}\right]
$$

Taking expectations over the above equation and defining it as a value $V$ we obtain:

$$
V\left(S_{t}, p_{t+1}\right)=S_{t}^{\prime} M\left(p_{t+1}\right)^{\prime} W M\left(p_{t+1}\right) S_{t}+E\left[w_{t+1}^{\prime} B^{\prime} C\left(p_{t+1}\right)^{\prime} W C\left(p_{t+1}\right) B w_{t+1}^{\prime}\right]
$$


where we used the fact that $w_{t+1}$ are i.i.d shocks to eliminate the cross terms. Note that the $p_{t+2}$ here will depend on the outcome of $w_{t+1}^{\prime}$ and the true model.

\section{B.3.2 Value Conditional on True Model}

Here we use $p_{t+1}$ to refer to the probability of the event that $\mathrm{A}$ is the true model. The value of the Central Bank's problem conditional on the event that the true model is $A$ is given by:

$L_{t \mid A}\left(S_{t}, p_{t+1}\right)=V\left(S_{t}, p_{t+1} \mid A\right)+\beta E\left[\left(p_{t+1}\right) L_{t+1 \mid A}\left(S_{t+1}, p_{t+2}\right)+\left(1-p_{t+1}\right) L_{t+1 \mid B}\left(S_{t+1}, p_{t+2}\right) \mid A\right]$ and

$L_{t \mid B}\left(S_{t}, p_{t+1}\right)=V\left(S_{t}, p_{t+1} \mid B\right)+\beta E\left[\left(p_{t+1}\right) L_{t+1 \mid A}\left(S_{t+1}, p_{t+2}\right)+\left(1-p_{t+1}\right) L_{t+1 \mid B}\left(S_{t+1}, p_{t+2}\right) \mid B\right]$

Both value functions can be obtained via standard methods of computation of value functions. 


\section{Approximation of Robust Policies - Value Function Method}

In appendix B we have showed how to compute $L_{\bar{p}_{\tau} \mid, A}$ and $L_{\bar{p}_{\tau} \mid B}$. In this section we explain the numerical procedure to compute $L_{\bar{p}_{\tau} \mid, A^{-}} L_{\bar{p}_{\tau} \mid B}$.

The procedure for the numerical solution of this problem is:

\section{Algorithm}

1. First, discretize the exogenous state space using Tauchen's method. The relevant space is: $S^{*}=\left\{\varepsilon_{\pi, t-1}, \varepsilon_{y, t-1}, r_{t-1}^{n}, i_{t-1}^{*}, \varepsilon_{e, t-1}, \tilde{\varepsilon}_{y, t-1}\right\}$.

2. We model prior space according to Chebyschev nodes.

3. Use an initial guess for the two Value Functions indexed by their corresponding model priors: $L_{t \mid A}(\cdot, \cdot)$ and $L_{t \mid B}(\cdot, \cdot)$.

4. Define a closed loop to satisfy a convergence condition for the guess in $L_{t \mid A}(\cdot, \cdot)$ and $L_{t \mid B}(\cdot, \cdot)$.

5. Define an Inner Loop over all model prior probabilities and exogenous state sock grids.

6. Define and Open Loop for draws in $w_{t+1}$, using 1000 draws.

7. Draw a random sample of $w_{t+1}$ where this variable is five dimensional normal standard vector.

8. Compute $w_{t+1}^{\prime} B^{\prime} C\left(p_{t+1}\right)^{\prime} W C\left(p_{t+1}\right) B w_{t+1}^{\prime}$, use $w_{t+1}^{\prime}$ to update $p(t+2)$ given $p(t+1)$, for model A and Model B.and the point in state $S^{*}$.

9. Update the point $S^{*}$, and use update points in $[0,1] \times S^{*}$ and evaluate them at $L_{t \mid A}(\cdot, \cdot)$ and $L_{t \mid B}(\cdot, \cdot)$ using an interpolation method. Save the outcome.

10. Compute the mean of the outcomes in $8-9$, and use these to update the guess values in the grid space for $L_{t \mid A}\left(S_{t}, p_{t+1}\right) \times L_{t \mid B}\left(S_{t}, p_{t+1}\right)$.

11. Repeat 5-10 until convergence.

Once the value functions are computed, we use them to compute a solution to 10. 